archives-ouvertes

\title{
Inhibition and oscillations in the human brain tissue in vitro
}

\author{
Liset Menendez de la Prida, Gilles Huberfeld
}

\section{To cite this version:}

Liset Menendez de la Prida, Gilles Huberfeld. Inhibition and oscillations in the human brain tissue in vitro. Neurobiology of Disease, Elsevier, 2019, 125, pp.198-210. 10.1016/j.nbd.2019.02.006 . hal02339682

\section{HAL Id: hal-02339682 \\ https: / hal.sorbonne-universite.fr/hal-02339682}

Submitted on 30 Oct 2019

HAL is a multi-disciplinary open access archive for the deposit and dissemination of scientific research documents, whether they are published or not. The documents may come from teaching and research institutions in France or abroad, or from public or private research centers.
L'archive ouverte pluridisciplinaire HAL, est destinée au dépôt et à la diffusion de documents scientifiques de niveau recherche, publiés ou non, émanant des établissements d'enseignement et de recherche français ou étrangers, des laboratoires publics ou privés. 


\section{Inhibition and oscillations in the human brain tissue in vitro}

Liset Menendez de la Prida ${ }^{1}$ and Gilles Huberfeld ${ }^{2,3}$

${ }^{1}$ Instituto Cajal, CSIC. Ave Doctor Arce 37. Madrid 28002. Spain

${ }^{2}$ Clinical Neurophysiology department, Pitie-Salpetriere Hospital, Sorbonne Université, APHP, Paris 75013, France

${ }^{3}$ Neuroglial Interactions in Cerebral Physiopathology, Center for Interdisciplinary Research in Biology, Collège de France, CNR UMR 7241, INSERM U1050, Labex Memolife, PSL Research University, Paris 75005, France.

\section{Corresponding authors:}

Liset Menendez de la Prida

Instituto Cajal, CSIC, Ave Doctor Arce, 37, Madrid 28002, Spain

Email: Imprida@cajal.csic.es

Tel: +34915854359

Gilles Huberfeld

Clinical Neurophysiology department, Pitie-Salpetriere Hospital, Sorbonne Université, APHP, 4783 Bd de l'Hopital, Paris 75013, France

Email: gilles.huberfeld@sorbonne-universite.fr

Tel: +33142161946

Metrics:

Word numbers: Highlights: 37, Abstract: 150, manuscript: 7764 (without references)

References: 205.

\section{Highlights:}

- Local microcircuits support oscillations generated in postoperative brain tissue

- Specialized microcircuits are identified in the human brain in vitro

- Defects of chloride regulation are involved in most epileptiform activities

- Oscillations and epileptiform activities may share microcircuit dynamics

Keywords: Human brain slices, Theta, Gamma, Ripples, Interictal, GABA 


\begin{abstract}
Oscillations represent basic operational modes of the human brain. They reflect local field potential activity generated by the laminar arrangement of cell-type specific microcircuits interacting brainwide under the influence of neuromodulators, endogenous processes and cognitive demands. Under neuropathological conditions, the spatiotemporal structure of physiological brain oscillations is disrupted as recorded by electroencephalography and event-relate potentials. Such rhythmopathies can be used to track microcircuit alterations leading not only to transient pathological activities such as interictal discharges and seizures but also to a range of cognitive co-morbidities. Here we review how basic oscillatory modes induced in human brain slices prepared after surgical treatment can help us to understand basic aspects of brain function and dysfunction. We propose to overcome the traditional view of examining human brain slices merely as generators of epileptiform activities and to integrate them in a more physiologically-oriented oscillatory framework to better understand mechanisms of the diseased human brain.
\end{abstract}




\section{Brain oscillations as biomarkers of microcircuit function and dysfunction}

The human brain activity spectrum ranges from very slow to very fast oscillations in association with different cognitive demands and physiological stages. Oscillations $<1 \mathrm{~Hz}$ are characteristic of slow-wave sleep and associated with up and down membrane potential fluctuations (Steriade et al., 2001). While they involve thalamo-cortical circuits (Crunelli and Hughes, 2010), intra-cortical networks contribute by organizing activity across deep and superficial layers in a state-dependent manner (Cash et al., 2009; Csercsa et al., 2010; Hangya et al., 2011). In turn, slow oscillation propagates brain-wide to play roles in regulating synaptic homeostasis (Massimini et al., 2004). Intermediate neocortical oscillations from theta $(4-8 \mathrm{~Hz})$ to alpha $(7-12 \mathrm{~Hz})$ frequencies are dynamically associated to specific cognitive demands (Canolty et al., 2006; Raghavachari et al., 2001). In the human hippocampus, short theta bouts organize neuronal spike timing during spatial and visual navigation as well as memory traces (Bohbot et al., 2017; Jutras et al., 2013; Rutishauser et al., 2010). Perceptual processing associated with neocortical rhythms in the alpha-beta band $(12-30 \mathrm{~Hz})$ are associated with rhythmic inhibition and phase-locked firing (Haegens et al., 2011), a mechanism shared with gamma $(40-80 \mathrm{~Hz}$ ) rhythms (Jacobs et al., 2007; Le Van Quyen et al., 2010). Faster oscillations $(>150 \mathrm{~Hz})$ are locally restrained in the hippocampus and neocortical regions serving memory consolidation processes (Kucewicz et al., 2014; Zhang et al., 2018).

Critically, these cognitive operations require coordinated activity across brain regions, believed to be reflected as a hierarchical and dynamical oscillatory coupling (Clemens et al., 2007; Fell et al., 2001; Lakatos et al., 2005; Staresina et al., 2015). Theta-gamma interaction coordinates local microcircuits across neocortical territories (Canolty et al., 2006). Top-down and bottom-up processing implicates coordination between alpha-beta and gamma rhythms across prefrontal, parietal and occipital cortices (Buschman and Miller, 2007; Michalareas et al., 2016). Different types of oscillatory coupling from phase-amplitude modulation to period concatenation may result from inter-laminar and inter-regional specific connections (Kramer et al., 2008; Palva et al., 2005). Not surprising, dynamical patterns of oscillatory coupling predicts cognitive operations better than power spectral features alone (Jensen and Colgin, 2007; Bohbot et al., 2017; Jutras et al., 2013; Rutishauser et al., 2010).

Oscillations recorded with intracranial electrodes predominantly reflect post-synaptic activity and transmembrane currents from local generators, with a strong contribution of inhibitory potentials, whereas scalp electroencephalography and subdural electrocorticography are biased by volume conducted activity from superficial cortical layers and large amplitude potentials (Buzsáki et al., 2012; Teleńczuk et al., 2017). Given the close relationship between oscillations and microcircuit function, they can be considered as biomarkers of neuropathological processes of brain diseases (Buzsáki, 2015; Palop and Mucke, 2016; Shuman et al., 2017). Similar to the normal brain, the epileptic brain may be considered an oscillatory system itself (Baud et al., 2018; de la Prida, 2018). The more we learn about the mechanisms underlying brain rhythms, the more we know about how deviations from the physiological function would transform the oscillatory spectrum. In temporal lobe epilepsy (TLE), a disease affecting the hippocampus and parahippocampal regions specifically, ripples $(150-250 \mathrm{~Hz})$ invade the fast ripple band $(>250 \mathrm{~Hz}$; (Jefferys et al., 2012; Worrell et al., 2008)). These pathological high-frequency oscillations (HFOs) are associated with epileptogenic areas and seizure onset zones and linked with hippocampal sclerosis (Staba et al., 2007; Zijlmans et al., 2012). Other oscillatory bands, including theta and gamma, are equally impaired in the epileptic hippocampus and slow theta-gamma modulation supporting episodic memory encoding is deficient in the human TLE (Lega et al., 2015). In experimental models of TLE, spatiotemporal features of theta, gamma and ripple oscillations are 
associated with a range of cognitive co-morbidities (Lopez-Pigozzi et al., 2016; Shuman et al., 2017; Valero et al., 2017).

Oscillations are particularly useful to track for changes of brain activity such as those accompanying seizures. Seizures are highly dynamic heterogenous phenomena at the cellular and network levels. They may result either from an excess of excitatory processes, from a deficiency/breakout of inhibitory control and/or from post-inhibitory rebounds. When the ictal discharge propagates brain-wide, different wavefront dynamics distinguish between the onset zone and surrounding territories based on the amount of cross-frequency interactions between slow and fast oscillations (Alvarado-Rojas et al., 2015; Weiss et al., 2013). The interictal state between seizures is characterized by the ability of the epileptic brain to generate short lasting hypersynchronized discharges accompanied by pathological HFOs. The hallmark of interictal discharges is their briefness, limited to 80-100 milliseconds, resulting in a large sharp wave typically called 'spike' that can be volume conducted to distant regions. They can also synaptically propagate following long-range connections brain-wide to affect memory function (Gelinas et al., 2016). Interictal discharges are followed by a slow component, or 'wave', lasting up to hundreds of milliseconds. The combination of both events, known as the spike-wave complex, can remain isolated or recur at variable frequencies from 3 to $10 \mathrm{~Hz}$. In focal epilepsies, spike and wave complexes are generated within the irritative zone generally overlapping the seizure onset zone (Rosenow and Luders, 2001). They are therefore considered as good markers of epileptogenic activity but have a poor localizing value. In contrast, patterns of fast oscillations characteristic of local epileptogenic microcircuits are gaining support as new biomarkers of epileptogenic regions (Jobst and Engel, 2015) although they are not obtained by scalp recordings.

Understanding basic mechanisms of human brain oscillations and their relationship with disease-specific rhythmopathies and epileptic forms of activity will help to improve functional diagnostic tools and to better identify shared anatomical, biochemical and physiological correlates of such rhythmopathies and epileptic discharges, ignored so far.

\section{Studying oscillations in human brain slices}

Surgical treatment of refractory epilepsies and brain tumors offers a unique opportunity to study the human brain ex vivo. Patients undergoing surgery exhibit a range of clinical background and pathologies allowing for testing disease-specific aspects of microcircuit organization using state-of-the-art in vitro techniques. In some cases, the resected tissue also includes nonpathological normal-like regions surrounding a non-epileptic lesion or located on the way to deep surgical targets, permitting examination of human microcircuit function in a context considered as physiological. The morphological normality may however not exclude that some tissues may be remodeled by epileptogenesis, specifically around gliomas known to produce in vivo pathological activities from remote areas (Mittal et al., 2016). After sectioning, brain slices from 300 to $500 \mu \mathrm{m}$ are stabilized in artificial cerebrospinal fluid (ACSF) at different flow rates in either submerged or interface chambers for subsequent electrophysiological recordings. Some reviews cover methodological aspects of classical human brain slice approaches (Jones et al., 2016; Kohling and Avoli, 2006). More recently, organotypic human brain cultures have allowed for cell-type specific genetic interventions and more sophisticated functional experiments such as optogenetics, chemogenetics and multi-cellular imaging (Andersson et al., 2016; Eugène et al., 2014; Le Duigou et al., 2018; Parker et al., 2017; Schwarz et al., 2017). New stem cell technologies now allow generation of brain organoids from human pluripotent cells (Lancaster and Knoblich, 2014). These 
emerging technologies will soon add to the arsenal of in vitro methodologies that can be brought to studying human tissue at an unprecedented scale.

A range of brain oscillations can be modeled in vitro using different ACSF composition and reagents (Table). Using different concentration of potassium $\left(\mathrm{K}^{+}\right)$, calcium $\left(\mathrm{Ca}^{2+}\right)$ and magnesium $\left(\mathrm{Mg}^{2+}\right)$ allows for recording self-organized oscillations in the local field potentials (LFP). The physiological or pathological nature of these oscillations will depend on how the different ionic composition affects excitability and synaptic transmission (Aivar et al., 2014; Lux et al., 1986). For instance, reducing $\mathrm{Ca}^{2+}$ and $\mathrm{Mg}^{2+}$ have a profound impact on synaptic transmission in slices from healthy rodents, causing pathological-like activities to emerge (Heinemann et al., 1992; Mody et al., 1987). Other factors such as the flow rate and interface conditions can affect the physiological level of oxygenation and $\mathrm{pH}$ required for a normal microcircuit operation (Hájos and Mody, 2009; Huchzermeyer et al., 2008). In slices prepared from different patients, and even within a given patient, variability observed under the same recording conditions may reflect different degrees of the underlying pathology in the resected block, together with technical irregularities (Menendez de la Prida et al., 1998). Therefore, it is advisable to use standard ACSF solutions that have been proven to operate at the physiological regime in order to extract meaningful conclusions regarding the pathophysiological mechanisms.

A full range of oscillations recorded intraoperatively can be mimicked in slices (Fig.1). Slow oscillations are typically recorded under standard ACSF in interface conditions and highflow rates both in fresh and organotypic slices (Table). Similar to rodent, activity from deep cortical layers variably contributes to trigger propagating waves in human neocortical slices (Florez et al., 2015; Sanchez-Vives and McCormick, 2000). In many reports (Florez et al., 2013; Kohling et al., 1998), they typically consist on recurrent spontaneous sharp-waves associated with composite synaptic currents that rhythmically reverse at around $-70 \mathrm{mV}$, the expected value of GABAa receptors. These events are blocked by GABAa antagonists like bicuculline or picrotoxin but also by antagonists of glutamatergic AMPA receptors such as CNQX (Graebenitz et al., 2011; Kohling et al., 1998). Since spontaneous slow oscillations were not reported to systematically correlate neither with etiology nor with histopathological findings (Florez et al., 2013; Kohling et al., 1998) they could be considered a basic operational mode of local microcircuits. Importantly, inhibitory potentials in resected human tissues are variable with distinct reversal potentials in pyramidal cells. In slices from epileptogenic territories, a subpopulation of pyramidal cells may be driven by depolarizing effects of GABAa receptors and reestablishing normal intracellular chloride concentration pharmacologically blocks recurring rhythmic events (Huberfeld et al., 2007; Pallud et al., 2014b). In human hippocampal slices, sharp-waves recur at similar slower frequencies and involve similar inhibitory and excitatory potentials than slow cortical waves but they are more typically considered interictal-like events given their association with altered GABAa-mediated inhibition (Alvarado-Rojas et al., 2015; Huberfeld et al., 2007). Thus, it may be hypothesized that in epileptogenic hyperexcitable regions or when chloride dysregulation affects GABAergic signaling towards depolarizing responses, slow oscillations could be transformed into recurrent interictal-like events of shorter duration and higher amplitude (Florez et al., 2015; Huberfeld et al., 2007).

Similar to healthy rodent slices, human neocortical slices bathed with kainate (50-100 nM) and/or carbachol $(50 \mathrm{nM})$ can generate spontaneous intermediate oscillations in the theta band (4-8 Hz) (Florez et al., 2015) (Table). These extracellular oscillations are associated with rhythmic intracellular inhibitory potentials and/or currents sensitive to antagonists of muscarinic receptors, consistent with their induction by cholinergic activation. Similar to slow oscillations, they are typically initiated in deep neocortical layers. Unlike rodent slices, carbachol alone increases multi- 
unit firing in superficial layers of human neocortical slices but remains subthreshold for the generation of oscillatory activity from deep layers (Florez et al., 2015). Interestingly, manipulations that induced theta activity also results in coupled oscillations in the beta $(12-30 \mathrm{~Hz})$ and gamma band $(40-80 \mathrm{~Hz})$. In human neocortical slices, gamma oscillations emerge with kainate alone independently in superficial and deep layers (Florez et al., 2015). As far as we know, there is no report of theta/gamma oscillations induced in human hippocampal slices.

High-frequency oscillations in the form of ripples associated to sharp-waves are more typically seen in human hippocampal slices (Alvarado-Rojas et al., 2015) (Table). Hippocampal ripples recorded in the subiculum of TLE patients correlate with intrinsic bursts and rhythmic inhibitory and excitatory potentials at the single-cell level (Alvarado-Rojas et al., 2015). These events are blocked by antagonists of glutamatergic and GABAergic receptors, supporting their microcircuit origin (Cohen et al., 2002). In rodents, both the spectral components and cellular correlates of physiological ripples appear similar to some interictal-like ripples recorded in human hippocampal slices (Ellender et al., 2010; Schlingloff et al., 2014; Valero et al., 2015). In the rodent sclerotic hippocampus, fast ripples and HFOs coexist with physiological-like ripples both in vivo and in vitro (Foffani et al., 2007; Valero et al., 2017). Therefore, it is possible that similar circuits can generate both types of events but separation based on spectral features remain challenging (Menendez de la Prida et al., 2015).

Interictal- and ictal-like discharges can be recorded spontaneously in slices from epileptic animals and in humans but they may also be generated pharmacologically in normal tissues, especially after blockade of GABAa receptors, a condition which however elicits almost exclusively interictal discharges ( $\mathrm{Li}, 1959)$ (Table). Interictal-like events are associated with a paroxysmal depolarization shift composed of a depolarizing envelope surmounted by bursts of action potential underlying extracellular ripples, fast ripples and pathological HFOs (Ayala et al., 1973; Jefferys et al., 2012). Both the induction by GABAa antagonists and the cellular signature led to a proposed mechanism involving a defective GABAergic inhibition and an excess in glutamatergic excitation (Prince and Connors, 1986) that could be summarized as a synchronized giant excitatory synaptic potential (Johnston and Brown, 1981). The secondary slow wave component rather represent inhibitory mechanisms particularly involving GABAb transmission (Cohen et al., 2006; de La Prida et al., 2006; Destexhe, 1998). In fact, depending on the pharmacological method for inducing interictal-like discharges in vitro, different mechanisms have been described (Rutecki et al., 1990, 1987, 1985). Altered GABAergic potentials in some human hippocampal pyramidal cells support pro-epileptogenic changes of GABAa-mediated inhibition caused by alterations of potassiumchloride cotransporter KCC2 and the sodium-potassium chloride cotransporter NKCC1 (Huberfeld et al., 2007). Consistently, rhythmic sharp-wave ripples and fast ripples are sensitive to bumetanide in the human epileptic hippocampus (Huberfeld et al., 2007). In epileptogenic territories from both neocortical and hippocampal human slices, fast oscillations are also sensitive to gap junction blockers (Simon et al., 2014).

Thus, as in the human brain in vivo, the postoperative tissue in vitro exhibits physiologicaland pathological-like oscillations coexisting with epileptiform activities. Presumably, the same microcircuits responsible for the basic oscillatory modes should operate during pathological forms of activity (Beenhakker and Huguenard, 2009; Paz and Huguenard, 2015) but these two conceptual frameworks have been traditionally separated in clinical research. There is no reason to think the brain operates independent mechanisms for normal and abnormal microcircuit function. Instead, by understanding how neuropathological territories are pushed away to operate in their physiological regime we will be able to better embrace the complexity of the human brain in health 
and disease (Scott et al., 2018). The study of basic neurophysiological mechanisms underlying brain disorders may rather benefit from such an integrated view.

\section{Microcircuit correlates of network oscillations in human brain slices: what is normal and what is not?}

What are the basic microcircuit mechanisms underlying oscillations in the human brain in vitro? How do they deviate from physiological-like behavior? In vitro investigation of human brain tissue may help to understand basic principles of microcircuit operations and their alterations in disease. Given the difficulties in evaluating normal-like brain tissue, we need to identify what is physiological and what is not in terms of different oscillatory patterns by comparison with in vivo human recordings and animal data. In human brain slices prepared from resected tissue, an additional influence of disease-specific neuropathology should be always considered although pathological-like oscillations, such as epileptic activities, may be associated with no obvious neuropathological defect. Thus, the critical point is to adopt a phenomenological approach to understand what is normal and what is not at the single-cell and microcircuit level in vitro and to identify potentially cell-type and connectivity specific drivers of physiological-like activities.

Similar to human intracranial recordings, slow neocortical oscillations in vitro are associated with fluctuating levels of firing rate across layers. Intracellular data support interpretation of synaptic influences during these fluctuating states (Florez et al., 2015; Kohling et al., 1999). During up states in vivo, large sinks recorded at superficial layers II-III are consistent with inward depolarizing currents flowing into the dendrites of superficial and deep pyramidal cells (Csercsa et al., 2010; Staba et al., 2002). These sinks are followed by prominent sources accompanied by neuronal silence consistent with hyperpolarized inhibitory currents (Cash et al., 2009; Csercsa et al., 2010). Interplay between GABAa- and GABAb-mediated inhibition plays complementary roles in balancing up and down states (Mann et al., 2009). While GABAa-mediated inhibition is involved in controlling neuronal firing precisely during up states, the slow dynamics of GABAb receptor currents acts to prolong membrane potential hyperpolarization and to modulate dendritic electrogenesis (PérezGarci et al., 2006). Dendrites of human pyramidal cells, especially from layer V, exhibit distinctive integrative features and enhanced input compartmentalization, a property that could change across regions (Beaulieu-Laroche et al., 2018; Eyal et al., 2016; Kim et al., 2015). A specialized human GABAergic cell from layer I can target the apical dendrites of layer III pyramidal neurons to inhibit back propagating action potentials (Boldog et al., 2018). Thus, disparities regarding the role of deep and superficial layers in the generation of slow oscillations across species and between preparations (in vivo, in vitro, anesthesia) may reflect regional differences in the cytoarchitectonic organization of cortical areas (Amzica and Steriade, 1998; Chauvette et al., 2010; Halgren et al., 2018; Sakata and Harris, 2009). In general, appropriate firing modulation during up/down states across layers is indicative of healthy territories whereas their absence may reflect microcircuit alterations (Csercsa et al., 2010). Thus, independently on the origin of slow oscillations, coherent modulation of cell-type specific firing can be considered a physiological-like treat.

Laminar interaction between deep and superficial layers appear critical in hierarchically organizing low and high frequency oscillations both in human and rodent neocortices. Human slices bathed with standard ACSF generate different degree of multi-unit firing during up states but not necessarily genuine LFP oscillations. Manipulations that increase intrinsic excitability and synaptic transmission, such as higher ionic composition of $\mathrm{K}^{+}(4-6 \mathrm{mM})$ and $\mathrm{Ca}^{2+}$ (2-4 mM) or low concentration of kainate (50-100 nM) may help eliciting bonna fide waves in the gamma range. The 
amplitude of these oscillations couples to the phase of slow wave activity that modulates neuronal firing (Beltramo et al., 2013; Florez et al., 2015; Halgren et al., 2018; Ulbert et al., 2004). Thus, elevated phase-amplitude coupling likely correlate with escalating levels of excitability in in vitro human data (Alvarado-Rojas et al., 2015; McGinn and Valiante, 2014), which in pathological conditions would tend to reflect exacerbated synaptic activity and excessive neuronal firing (Tort et al., 2013).

Appropriately regulated gamma oscillations are associated with the integrity of GABAergic mechanisms (Vida et al., 2006). Two main mechanisms support gamma oscillations: the interneuron-interneuron gamma model (ING) and the pyramidal cell-interneuron gamma (PING) that emerges from recurrent connections between glutamatergic and GABAergic cells (Buzsáki and Wang, 2012) (Fig.2A). Depolarizing tonic inputs resulting in interneuronal firing may suffice to entrain an interconnected network of interneurons at the temporal scale of the intrinsic time constant of GABAa-mediated inhibitory currents. In PING models, activity of pyramidal cells drives recurrent networks to oscillate. Thus, the organization of local microcircuits may determine the ability of different neocortical territories to generate gamma oscillations in vitro (Buzsáki and Wang, 2012; Vida et al., 2006). Kainate receptor agonists activate directly interneurons while cholinergic agonists may require additional depolarization of the whole neuronal population (Fisahn et al., 2004; Florez et al., 2015). In human slices, cholinergic drive may act directly over upper layer latespiking neurogliaform cells and onto Martinotti cells to facilitate local and lateral inhibition (Obermayer et al., 2018; Poorthuis et al., 2018). Neurogliaform cells are a major source of slow extrasynaptic GABAa-mediated postsynaptic responses (Szabadics et al., 2007; Tamás et al., 2003) and GABAb-mediated pre- and postsynaptic inhibition (Craig and McBain, 2014; Tamás et al., 2003). Predominance of gamma activity in upper cortical layers of the human neocortex can also reflect variabilities in the number of calretinin- or reelin-immunopositive interneurons in this zone (Gabbott et al., 1997; Varga et al., 2015). Calretinin+ cells and/or VIP-expressing interneurons preferentially targeting other local GABAergic cells would provide additional substrates for ING mechanisms (del Río and DeFelipe, 1997).

In general, physiological-like high-beta and gamma oscillations also reflect fast sequences of excitatory and inhibitory potentials at the fast gamma band (Fig.2A). In this oscillatory PING regime, the delay between excitation and inhibition is critical to determine phase response dynamics (Akao et al., 2018; Fuchs et al., 2007). In superficial layers of human neocortex, individual action potentials from pyramidal cells can initiate complex network events caused by the efficient recruitment of GABAergic interneurons (Molnár et al., 2008; Szegedi et al., 2017). Human calretinin+ interneurons co-expressing the transcription factor COUP-TFII are able to activate inhibitory potentials in the dendrites of reciprocally connected pyramidal cells (Varga et al., 2015). Perisomatic inhibition initiated synchronously by individual parvalbumin+ basket cells in subsets of pyramidal cells has proved effective for gamma (Bartos et al., 2001). Thus, different human interneuronal subtypes may play specific roles in generating and maintaining neocortical gamma oscillations. Subtle regional differences in the organization of local GABAergic and glutamatergic microcircuits may operate in the diseased human brain (Alonso-Nanclares et al., 2005; DeFelipe et al., 1994, 1993; Foehring et al., 1991; Menendez de la Prida et al., 2002).

A repertoire of fast events including spindles (7-14 Hz), gamma bouts and ripples could naturally couple to slow neocortical oscillations (Csercsa et al., 2010), but depending on the excitability level and the integrity of GABAergic mechanisms these events could reflect abnormal synchronous firing in epileptogenic territories (Alvarado-Rojas et al., 2015; Kohling et al., 1999). Epileptiform activities are typically characterized by large amplitude and brief events accompanied by high-gamma oscillations $(90-150 \mathrm{~Hz})$, ripples and HFOs ( $>250 \mathrm{~Hz}$; (Jiruska et al., 2010), which 
in most cases are considered surrogates for neuronal bursting (McGinn and Valiante, 2014; Ray et al., 2008; Tort et al., 2013). Paired recordings in human neocortical slices showed that axoaxonic parvalbumin+ interneurons can initiate depolarizing synaptic events due the absence of KCC2 in the axon initial segment (Szabadics et al., 2006). Some groups have indeed suggested that population events recorded in the cortex could in fact correspond to physiological activities (Tóth et al., 2018), initiated by normal interneuronal firing located apart from the surgical target zone (Szegedi et al., 2016). Thus, together with pathological GABAa-mediated perisomatic depolarization this may yield to concatenated series of complex synaptic events across neighboring interneurons and pyramidal cells that invade the fast ripple band (Molnár et al., 2008). Channelopathies affecting intrinsic excitability and synaptic integration can also contribute to distort the high-frequency spectrum (Simeone et al., 2013). It has to be stressed however that these tissues are mainly obtained from peritumoral cortices, in which the epileptogenic processes develop at considerable distance of the tumor macroscopical limits. This has been shown in vivo during chronic (Mittal et al., 2016) and peroperative cortical recordings (Feyissa et al., 2018) of areas infiltrated by sparse tumor cells (Pallud et al., 2014b, 2010).

In summary, local microcircuits in the human brain are tuned to generate oscillations in the gamma and ripple band, whereas inter-laminar and inter-regional connectivity modulate local fast oscillations by slower frequency activity in the beta, theta and at $<1 \mathrm{~Hz}$ frequency band (Fig.1B). Understanding how activity is organized in upper and lower neocortical layers and within different structures such as in the hippocampus-entorhinal system requires better knowledge of regional differences on cell-type specificity and connectivity and how neuropathological changes do affect microcircuit function (Fig.1C). In general, a physiological regime of oscillations is reflected as an adequate balance between slow and fast oscillations keeping neuronal firing and bursting at a relatively low synchronization level. Sharp-wave events have moderate amplitudes in a range of few hundreds millivolts when measured locally with microelectrodes. Intermediate rhythms are well tuned by brain-wide slow frequency rhythms so that the depth of slow-frequency modulation of individual neurons is strong. In the diseased human brain, alterations of gamma activity and the higher frequency band are conspicuous, suggesting a shift towards high-frequency modulatory effects and pathological HFOs.

\section{Pathological forms of activity in the human brain in vitro}

From the sections above it seems clear that looking at the spatiotemporal oscillatory patterns in vitro may help to inform on potential pathophysiological alterations underlying human brain diseases. However, recordings from human epileptic postoperative tissues provide evidence that the diseased human brain in vitro is able to generate other pathological forms of activities (Fig.1). High-amplitude sharp-wave interictal-like activities have been observed in tissues obtained from patients undergoing surgery for pharmacoresistant temporal lobe epilepsy (frequently associated to hippocampal sclerosis) (Cohen et al., 2002; Gabriel et al., 2004; Huberfeld et al., 2007; Isokawa and Fried, 1996; Kivi et al., 2000; Kohling et al., 1999, 1998; Prince and Wong, 1981; Roopun et al., 2010; Schwartzkroin and Haglund, 1986; Schwartzkroin and Knowles, 1984; Schwartzkroin and Prince, 1976; Schwartzkroin et al., 1983; Wittner et al., 2009; Wozny et al., 2003), peritumoral cortices in low and high grade gliomas (Dossi et al., 2018; Pallud et al., 2014; Tóth et al., 2018), dysembryoplastic neuroepithelial tumors (Dossi et al., 2018) and focal cortical dysplasias (Dossi et al., 2018, 2014). These spontaneous events may be recorded from slices when neuronal viability is optimized by procedures improving oxygen availability, such as interface condition or high flow rates (Table). In these tissues, GABAa receptors antagonists rather control 
interictal activities and cellular recordings show that interneurons fire before the onset of the event, suggesting that these activities are driven by interneurons that depolarize pyramidal cells with defective chloride regulation (Cohen et al., 2002; Huberfeld et al., 2007; Pallud et al., 2014). In some cases such as recordings in the hippocampal spared CA2 region, excitatory glutamatergic signals seem preeminent (Wittner et al., 2009) and some authors have questioned the epileptic nature of the recorded field potentials given similarities with rodent physiology (Alvarado-Rojas et al., 2015; Tóth et al., 2018). The difficulties in assessing indubitable control human tissue make difficult to address directly this question. Interestingly, spontaneous interictal-like discharges are less conspicuously reported from slices obtained from animal models of epilepsy. In a mouse model of hippocampal epilepsy, hyperpolarizing post-synaptic currents are recorded in pyramidal cells during discharges but no clear depolarizing effects of GABA were demonstrated (Le Duigou et al., 2008). The complexity and variability of neuronal behavior during interictal discharges is supported by human cellular recordings in vivo in which neurons can either fire before, during the event or remain silent (Keller et al., 2010; Truccolo et al., 2011).

Transition from the interictal state to seizures has been studied extensively in vivo in patients to try to identify seizure anticipation markers (Kuhlmann et al., 2018). Mathematical descriptions of seizures suggest their dynamics can be reduced to few basic principles that scale invariantly from neurons to microcircuits and brain-wide networks (Jirsa et al., 2014). These basic principles can be summarized as the existence of coupled slow-fast dynamical processes that govern seizure initiation and termination. At any level (from neurons to networks), a slow variable may shift the system away from the equilibrium resulting in fast reverberating activity (oscillations) that somehow couples back to a slow process responsible for seizure offset. Slowly fluctuating processes leading to a seizure are responsible of pushing neurons away from the resting membrane potential towards the action potential threshold. Several mechanisms from DC shifts to buildup activity have been shown to precede seizures (Huberfeld et al., 2011; Sedigh-Sarvestani et al., 2014; Vanhatalo et al., 2003; Voipio et al., 2003). These mounting slow shifts result in accumulating depolarizations across different cell-types due to the integrative properties of membranes and synaptic potentials reverberating through local microcircuit interactions together with changes of the local microenvironment (Antonio et al., 2016; Avoli et al., 1995, 1987).

In epileptic human slices exhibiting spontaneous interictal discharges, seizure-like events are only recorded when elicited by a pharmacological increase of excitability using modified ACSF (Table) (Avoli et al., 2003; D'Antuono et al., 2004; Dossi et al., 2018; Gabriel et al., 2004; Huberfeld et al., 2011; Jandova et al., 2006; Pallud et al., 2014). The main characteristic of this period is the emergence of recurrent high amplitude events, similar to that preceding seizures and therefore named preictal discharges (Huberfeld et al., 2011). In vitro, preictal discharges propagate faster than interictal events and are more synchronous and widespread while in vivo they are rather localized to the seizure onset area. Both inter and preictal discharges are associated with a HFO signature centered on $250 \mathrm{~Hz}$ in the epileptic human subiculum (Alvarado-Rojas et al., 2015; Huberfeld et al., 2011) and the peritumoral cortex (Pallud et al., 2014) while in dysplastic tissues, fast ripples are only evident in preictal discharges (Blauwblomme and Huberfeld; unpublished observations). At a cellular scale, preictal discharges are rather initiated by pyramidal cells, widely synchronizing surrounding neurons through AMPA glutamatergic signals.

While interictal and preictal discharges are transient events, epileptic seizures are complex dynamic events with variable oscillatory components (Baud et al., 2018; Eissa et al., 2017; Jirsa et al., 2014; Wagner et al., 2015). The oscillatory pattern at seizure onset may reflect the neuronal and signaling behavior responsible for seizure generation. In TLE, two main seizure onset patterns 
have been described in both human and animals, in vivo and in vitro. In the hypersynchronous (HYP) pattern, the seizure is initiated by recurring bursts of activity at 3-15 Hz with dynamic modulation, while the low voltage fast activity (LVFA) pattern consists in fast discharges progressively emerging from HFO bursts (Bragin et al., 2005; Gotman et al., 1995; Spencer et al., 1992). The two patterns may be not so clearly distinguished since: a) series of preictal discharges may be followed by a fast activity onset (Weiss et al., 2016); b) the fast-low voltage activity may be initiated by a single transient large field potential and c) dissection of preictal discharges versus seizure onset hypersynchronous discharges may be misleading. In neocortical focal epilepsy, different oscillatory seizure-onset patterns may interact at multiple scales (Eissa et al., 2017; Wagner et al., 2015) and be affected by the underlying pathology (Perucca et al., 2014). We would therefore propose to distinguish clearly 1- LFVA onset seizures by events in which this fastoscillatory desynchronized component initiates the seizure, whether synchronized preictal discharges or a slow defection precedes this discharge or not from 2- HYP seizures that lack such tonic fast behavior and are launched by highly synchronized slowly oscillating bursts of discharge. These wo seizure pattern would clearly differentiate according to their field potential signature and to the neuronal synchronizing pattern which may reflect distinct neuronal behaviors.

Animal studies have suggested that both neuronal behavior and signaling may differ according to the seizure onset pattern. Although performed in normal animal by administration of convulsant, blockade of GABAa receptors was associated with a HYP onset while kainic acid injection rather determined LVFA pattern (Bragin et al., 2009). These data question the involvement of GABAergic interneurons versus pyramidal cells in the generation of seizures according to the oscillatory pattern and may possibly indicate different contribution by intra-laminar and interregional microcircuits. In vitro, in models of seizures induced by various convulsants, most seizures have a LVFA onset, eventually preceded by preictal spikes (leading to confusions in naming ictal patterns). In published cases, a strong interneuronal discharge is recorded at seizure onset (Fujiwara-Tsukamoto et al., 2007; Gnatkovsky et al., 2008; Ziburkus, 2006). In human data, microelectrode recordings are required to identify individual neuronal behavior (Lambrecq et al., 2017; Merricks et al., 2015; Truccolo et al., 2011; Weiss et al., 2016). Seizure events are far from recruiting all neurons and during the preictal period, single cell firing may increase, decrease or not change independently of the underlying pathology (Lambrecq et al., 2017; Truccolo et al., 2014, 2011). However, seizure initiation as well as progression in the neocortex as a wavefront is sustained by robust neuronal firing with local recruitment/synchronization of limited neuronal populations (Merricks et al., 2015; Schevon et al., 2012; Weiss et al., 2013) and failing inhibitory processes (Schevon et al., 2012; Weiss et al., 2013). In a recent study, the preictal period, the onset and the beginning of LVFA seizures were all associated with robust interneuronal firing, largely exceeding that of presumed pyramidal cells, both in the hippocampus, the amygdala and the entorhinal cortex (Elahian et al., 2018). These data claim for a clear involvement of interneurons in the generation of ictal activities but caution should be taken due to difficulties in unit isolation (Merricks et al., 2015). Spike sorting techniques may soon allow for reliable differentiation of interneurons vs pyramidal cells behavior during a seizure in vivo by improving sorting approaches (Niediek et al., 2016). The causality of interneuronal firing on seizure initiation per se cannot be assessed by observational recordings. GABAergic interneurons may inhibit other neurons but may also depolarize them in case of chloride dysregulation and contribute to local increase in extracellular potassium with additional excitatory effects. This question can be hardly addressed by in vivo recordings and requires complementary in vitro approaches using for example optogenetics (Andersson et al., 2016). 


\section{Inhibitory vs excitatory GABAergic signaling in epileptic tissues: where and when?}

Epilepsy-associated changes of GABAergic mechanisms have major impact in controlling oscillations and neuronal activity. Recordings from human postoperative epileptic tissues have greatly contributed to highlight depolarizing and possibly excitatory effects of GABA as a key epileptogenic mechanism. In all cases in which spontaneous interictal activities were recorded from human epileptic tissues, either from the subiculum or the neocortex, GABAa receptors blockade suppressed these discharges (Cohen et al., 2002; D'Antuono et al., 2004; Huberfeld et al., 2007; Kohling et al., 1998; Pallud et al., 2014; Roopun et al., 2010; Schwartzkroin and Haglund, 1986; Tóth et al., 2018; Wozny et al., 2003). When individual pyramidal cells were recorded, both depolarizing and hyperpolarizing post synaptic inputs were observed during interictal field potentials (Cohen et al., 2002; Huberfeld et al., 2011, 2007; Kohling et al., 1999, 1998; Prince and Wong, 1981; Roopun et al., 2010; Schwartzkroin and Haglund, 1986; Schwartzkroin and Knowles, 1984; Schwartzkroin and Prince, 1976; Wozny et al., 2003), suggesting that during these events a subset of pyramidal cells varying from 20 to $65 \%$ may be rather depolarized by GABA (Huberfeld et al., 2011, 2007). Recorded interneurons fired, with variable strength, at the onset of these discharges (Cohen et al., 2002; Huberfeld et al., 2011, 2007; Pallud et al., 2014; Roopun et al., 2010) and hyperpolarization of parvalbumin interneurons by the $\mu$ opioid agonist DAGO suppressed interictal discharges (Pallud et al., 2014) emphasizing the hypothesis of a network activity triggered by interneurons. In vivo investigations of interneuronal firing dynamic is only available in an animal model of epilepsy (pilocarpine) but clearly showed by calcium imaging that "GABAergic neurons are the main participants in interictal spikes in CA1" (Muldoon et al., 2015). Depolarizing responses to GABA are related to chloride dysregulation in mature neurons, although, according to chloride, neuronal maturation is a very early process (Dzhala et al., 2005). Such dysregulation results mainly from an increased expression of the chloride cotransporter NKCC1, loading neurons with chloride, and from a down regulation or decreased efficiency of its counterpart $\mathrm{KCC} 2$, responsible for chloride outload.

A depolarization shift of chloride dependent GABAergic currents due to increased intraneuronal concentration is well documented in various types of human epileptic tissues (Alvarado-Rojas et al., 2015; Cohen et al., 2002; Huberfeld et al., 2011, 2007; Pallud et al., 2014b). $\mathrm{KCC} 2$ has been shown to be down-regulated in the human epileptogenic hippocampus, subiculum or temporal neocortex (Huberfeld et al., 2007; Muñoz et al., 2007; Palma et al., 2006), from patients with tumor related epilepsies (Conti et al., 2011;Pallud et al., 2014), focal cortical dysplasias (Aronica et al., 2007; Jansen et al., 2010; Munakata et al., 2007; Shimizu-Okabe et al., 2011; Talos et al., 2012) and tuberous sclerosis (Talos et al., 2012). A single study has reported so far an upregulation in the epileptic temporal lobe (Karlócai et al., 2016). NKCC1 expression, although difficult to study due to lack of specific antibody and to expression of both neuron and astrocytes in the central nervous system, has been reported to be up-regulated in temporal lobe epilepsies (Huberfeld et al., 2007; Muñoz et al., 2007; Palma et al., 2006), peritumoral neocortex (Conti et al., 2011; Pallud et al., 2014), focal cortical dysplasias (Aronica et al., 2007; Jansen et al., 2010; Sen et al., 2007; Shimizu-Okabe et al., 2011; Talos et al., 2012), and tubers (Talos et al., 2012). Blockade of NKCC1, reestablishing normal chloride concentrations, by the diuretic bumetanide has also been shown to block interictal activities (Huberfeld et al., 2007; Pallud et al., 2014; Talos et al., 2012).

Different methodological concerns question data on intracellular chloride disruption. Population events recorded in human slices may be related to injuries due to the slicing procedure (Dzhala et al., 2012), disrupting chloride regulation and artificially determining excitatory responses to GABA. These activities are however never recorded from normal animal brain slices, nor from 
human control tissues obtained by the resection of non-epileptic neocortex, surrounding brain lesions or on the way to access them (Dossi et al., 2018; Pallud et al., 2014b), although they may be involved in seizure propagation (Wang et al., 2017). Depolarizing effects of GABA as well as epileptic activities are recorded deep within slices, while the trauma affecting chloride regulation is reported at about $50 \mu \mathrm{m}$ beneath the slice surface. When resected tissue is sliced, epileptiform activities are located consistently in the block, suggesting that the defect is spatially constrained and unrelated to the slicing procedure. Up to $90 \%$ of the patients with low grade gliomas have seizures at surgery (Pallud et al., 2014) and epileptic activities are recorded in the areas surrounding glioma limits both in vivo and in vitro (Mittal et al., 2016; Pallud et al., 2014). Moreover, when tissues are exposed to proconvulsant ACSF, the only slices producing ictal-like events are those obtained from epileptic patients in which spontaneous interictal activities were recorded (Dossi et al., 2018; Huberfeld et al., 2011). Nevertheless, dual cortical or hippocampal in vivo/in vitro recordings in the same patients at comparable spatial scale should definitively resolve these issues.

Transition from interictal state, characterized by recurring interictal discharges (which can be considered as markers of epileptogenic tissues) to seizures is never spontaneous in vitro, highlighting that global fluctuations of brain excitability, whether endogenous or exogenous, are mandatory to trigger seizures (Huberfeld et al., 2013). While the seizure prediction field unraveled numerous mathematical concepts and tools to anticipate seizure occurrence (Jirsa et al., 2014; Lamberink et al., 2017), no clear biological phenomenon or oscillatory pattern has been identified so far and interictal basal discharges show various unpredictable dynamic patterns possibly reflecting different underlying microcircuits across regions and etiologies (de Curtis and Avoli, 2015). In vitro human tissues studies have contributed to emphasize a key oscillatory pattern, specific of the ictogenesis process: preictal discharges accompanied by HFOs (Huberfeld et al., 2011; Pallud et al., 2014b). Most seizures initiate from recurring preictal discharges but these population events are progressively generated earlier during the transition period. In vitro, preictal discharges are initiated by firing from some pyramidal cells able to synchronize local neurons, giving raise to high amplitude events (Huberfeld et al., 2011). During the transition period, preictal discharges progressively grow in amplitude while synchronizing increasing number of cells via an NMDA-dependent synaptic plasticity during periods lasting tens of minutes in vitro (Huberfeld et al., 2011). Once fully blown-up preictal discharges mainly recruit local cells by AMPA signals. It should be emphasized that they are not specific markers of epilepsy since human non-epileptic tissues may generate them by increasing excitability through ACSF modifications. However, in these non-epileptic tissues, they fail to trigger seizures, suggesting some potential collaborating mechanisms are required for ictogenesis, including chloride dysregulation and depolarizing effects of GABA represented by interictal discharges and resulting from epileptogenic remodeling (Huberfeld et al., 2011).

Seizure generation mechanisms have been studied in human epileptic tissues in vitro and fit with animal data reporting a leading role of interneurons and GABAergic input (Curtis and Avoli, 2016). Most seizure-like events induced in human epileptic by increasing excitability and/or neurotransmitter release trough low magnesium, low calcium, high potassium concentrations, alkalization or 4-aminopyridine application (Avoli et al., 1999, 1995, 1994, 1991, 1988, 1987; D'Antuono et al., 2004; Dossi et al., 2018; Gigout et al., 2006; Huberfeld et al., 2011; Hwa and Avoli, 1992; Klaft et al., 2016; Mattia et al., 1995), are preceded by preictal discharges firing and often start by a fast low voltage tonic discharge grafted on a preictal discharge. Animal data suggest that low magnesium condition would rather elicit HYP seizures while 4-AP rather induces LVFA seizures (Avoli et al., 2016). The same stimulus may however produce different seizure types in human tissues, with no clear effect of the underlying neuropathology (Dossi et al., 2018). While 
preictal discharges are associated with depolarizing excitatory input, they are not blocked by GABAa receptors antagonists or NKCC1 inhibition (Huberfeld et al., 2011) suggesting that they mostly depend on pyramidal cell firing and glutamatergic signaling. At seizure onset, preictal discharges are also associated with transient increases in extracellular potassium concentration (D'Antuono et al., 2004). The source of such potassium increase is thought to be related to interneurons both directly (potassium being released during high-frequency firing) and indirectly by exacerbated GABA release (chloride being then extruded together with potassium by the cotransporter KCC2) (Viitanen et al., 2010). Interneuronal firing appears to be mandatory in ictogenesis possibly operating as a synchronizing mechanism after inhibitory rebounds or tonically driving pyramidal cells, since the pre-synaptic $\mu$ opioid receptors agonist DAGO, which does not affect preictal discharges, blocks seizures (Avoli et al., 2002; D'Antuono et al., 2004; Gnatkovsky et al., 2008). The seizure onset itself, during the tonic discharge, is associated with a strong increase of extracellular potassium (D'Antuono et al., 2004). However, direct evidence of strong interneuronal discharge together with the initial silence of pyramidal cells, largely documented in rodents, has not been shown in human tissues yet. Interestingly, the initial phase of the tonic discharge is associated in human pyramidal cells with a membrane depolarizing potential shift compatible with outward chloride currents (Huberfeld et al., 2011). While AMPA and NMDA glutamatergic signaling contributes, the fact that GABAa receptors blockade, reduction of presynaptic GABA release by DAGO and reduction of chloride load by blocking NKCC1 all prevent seizures provide additional support to the leading role of GABAergic interneuronal activity in ictogenesis (D'Antuono et al., 2004; Huberfeld et al., 2011). Non synaptic mechanisms as gap junctions may further be involved and identified by HFOs in the $>80 \mathrm{~Hz}$ high frequency band (Gigout et al., 2006; Roopun et al., 2010; Simon et al., 2014). Seizures in human tissues have also been shown to be associated with a drop in extracellular calcium (Avoli et al., 1995, 1987) known to be associated with HFOs (Aivar et al., 2014).

Studying pathological forms of activities in the human brain in vitro can connect with the specific mechanisms pushing the human microcircuits to transiently operate outside their physiological-like oscillatory regime. Seizures, preictal and interictal events can all represent hyperexcitable states emerging from the very same altered microcircuits responsible for physiological rhythms underlying cognitive operation. Not rarely, neurological diseases correlate with a range of cognitive co-morbidities that can be associated with rhythmopathies of the natural oscillatory patterns. By integrating these two different perspectives, we can possibly better identify common and separate mechanisms of brain operation in health and disease.

\section{Conclusion}

This review reflects two different perspectives on human brain neurophysiology in vitro. The fact that postoperative human brain tissue can be only available from the surgical treatment of epilepsies and tumors has traditionally focused research in understanding basic pathophysiological mechanisms. More recently, by exploiting innovative approaches for intraoperative electrocorticography and intracranial microelectrode recordings coupled with detailed anatomical examinations of brain samples, a better delineation of pathological and non-pathological regions has allowed examining aspects of microcircuit function not addressed before. New cell-types and mechanisms supporting specialized human functions are now identified and integrated into the existing knowledge accumulated from animal research. In many cases, these tissues are presumed to reflect normal-like regions away from the neuropathological territories or on the way to the surgical targets. There is however no human brain tissue to control for neurophysiological studies 
and we must rely in an adequate assessment of what is normal and what is not in comparison with existing in vivo human and animal data.

From data reviewed above, we can extract some major criteria to help identifying physiological- and pathological-like oscillations and activities in human brain slices. Slow oscillations $(<1 \mathrm{~Hz})$ and intermediate theta oscillations of moderate amplitude and duration coupled to gamma oscillations can be considered a basic operational mode of human neocortical microcircuit. These oscillations can be induced in thick brain slices with standard ACSF supplemented by neuromodulatory agents such as cholinergic agonists such as carbachol. Using these approaches we can try understanding the contribution of different cell-types and regions to the generation of these rhythms and their distortion by the underlying neuropathology. In this regime, synchronization between neurons and across layers correlates with the degree of phaseamplitude coupling and neuronal excitability. The higher the firing rate the stronger the slow-fast modulation and the higher the contribution at the pathological HFO spectrum.

In the human hippocampus, the slow-fast coupled oscillatory regime is more typically associated with fast oscillations in the ripple band accompanying sharp-waves of moderate amplitude. Physiological-like ripples are associated with rhythmic inhibitory and excitatory potentials in a proportion of cells and with relatively low levels of excitability. Any sign of spectral contribution at the fast ripple band, or excessive bursting activity in pyramidal cells, accompanied by large amplitude sharp-waves and HFOs is indicative of a pathological condition. Further studies of the non-sclerotic hippocampus may help in trying understanding how physiological- and pathological-like forms of ripples are generated and coexists.

When normal excitability, connectivity and GABAergic transmission is compromised, either pharmacologically or due to the underlying neuropathology, physiological-like oscillations transform into pathological forms of activity in the form of HFOs, interictal-like and ictal-like activity patterns. A major mechanism in epileptic human tissue is an altered equilibrium for intracellular chloride that renders GABAa-mediated inhibition depolarizing and channelopathies affecting intrinsic excitability. It is important to bear in mind that pathological activities can be induced in healthy territories when the microcircuit is pushed away from the physiological regime of operation. In vivo recordings at similar scales that in vitro analysis may contribute to distinguish between physiological and pathological activities, to better delineate local oscillatory pattern, obviously different in human compared to rodents, to determine cellular behaviors underlying rhythms and finally to raise rhythmopathies as specific components of neurological diseases.

We propose that by integrating cell-type and microcircuit specific studies of physiologicaland pathological-like oscillations with the mechanisms of ictogenesis in the human brain in vitro we should advance the clinical neuroscience field beyond our current limits for a better understanding of brain function in health and disease.

Acknowledgements: We thank the Spanish Ministerio de Economía y Competitividad (BFU201566887-R) and the Fundación Tatiana Perez de Guzman el Bueno for supporting grants to LMP. 


\section{References}

Aivar, P., Valero, M., Bellistri, E., Menendez de la Prida, L., 2014. Extracellular calcium controls the expression of two different forms of ripple-like hippocampal oscillations. J. Neurosci. 34, 29893004.

Akao, A., Ogawa, Y., Jimbo, Y., Ermentrout, G.B., Kotani, K., 2018. Relationship between the mechanisms of gamma rhythm generation and the magnitude of the macroscopic phase response function in a population of excitatory and inhibitory modified quadratic integrate-and-fire neurons. Phys. Rev. E 97, 012209.

Alonso-Nanclares, L., Garbelli, R., Sola, R.G., Pastor, J., Tassi, L., Spreafico, R., DeFelipe, J., 2005. Microanatomy of the dysplastic neocortex from epileptic patients. Brain J. Neurol. 128, 158173.

Alvarado-Rojas, C., Huberfeld, G., Baulac, M., Clemenceau, S., Charpier, S., Miles, R., de la Prida, L.M., Le Van Quyen, M., 2015. Different mechanisms of ripple-like oscillations in the human epileptic subiculum. Ann. Neurol. 77, 281-290.

Amzica, F., Steriade, M., 1998. Electrophysiological correlates of sleep delta waves. Electroencephalogr. Clin. Neurophysiol. 107, 69-83.

Andersson, M., Avaliani, N., Svensson, A., Wickham, J., Pinborg, L.H., Jespersen, B., Christiansen, S.H., Bengzon, J., Woldbye, D.P.D., Kokaia, M., 2016. Optogenetic control of human neurons in organotypic brain cultures. Sci. Rep. 6, 24818.

Antonio, L.L., Anderson, M.L., Angamo, E.A., Gabriel, S., Klaft, Z.-J., Liotta, A., Salar, S., Sandow, N., Heinemann, U., 2016. In vitro seizure like events and changes in ionic concentration. J. Neurosci. Methods 260, 33-44.

Aronica, E., Boer, K., Redeker, S., Spliet, W.G.M., van Rijen, P. C., Troost, D., Gorter, J.A., 2007. Differential expression patterns of chloride transporters, $\mathrm{Na}+\mathrm{K}+-2 \mathrm{Cl}$ textminus-cotransporter and $\mathrm{K}+$-Clltextminus-cotransporter, in epilepsy-associated malformations of cortical development. Neuroscience 145, 185-196.

Avoli, M., Bernasconi, A., Mattia, D., Olivier, A., Hwa, G.G., 1999. Epileptiform discharges in the human dysplastic neocortex: in vitro physiology and pharmacology. Ann. Neurol. 46, 816-826.

Avoli, M., D’Antuono, M., Louvel, J., Kohling, R., Biagini, G., Pumain, R., D’Arcangelo, G., Tancredi, V., 2002. Network and pharmacological mechanisms leading to epileptiform synchronization in the limbic system in vitro. Prog Neurobiol 68, 167-207.

Avoli, M., de Curtis, M., Gnatkovsky, V., Gotman, J., Köhling, R., Lévesque, M., Manseau, F., Shiri, Z., Williams, S., 2016. Specific imbalance of excitatory/inhibitory signaling establishes seizure onset pattern in temporal lobe epilepsy. J. Neurophysiol. 115, 3229-3237.

Avoli, M., Drapeau, C., Louvel, J., Pumain, R., Olivier, A., Villemure, J.G., 1991. Epileptiform activity induced by low extracellular magnesium in the human cortex maintained in vitro. Ann. Neurol. 30, 589-596.

Avoli, M., Louvel, J., Drapeau, C., Pumain, R., Kurcewicz, I., 1995. GABAA-mediated inhibition and in vitro epileptogenesis in the human neocortex. J Neurophysiol 73, 468-484. 
Avoli, M., Louvel, J., Mattia, D., Olivier, A., Esposito, V., Pumain, R., D’Antuono, M., 2003. Epileptiform synchronization in the human dysplastic cortex. Epileptic Disord 5 Suppl 2, S45-50.

Avoli, M., Louvel, J., Pumain, R., Olivier, A., 1987. Seizure-like discharges induced by lowering [Mg2+]o in the human epileptogenic neocortex maintained in vitro. Brain Res. 417, 199-203.

Avoli, M., Mattia, D., Siniscalchi, A., Perreault, P., Tomaiuolo, F., 1994. Pharmacology and electrophysiology of a synchronous GABA-mediated potential in the human neocortex. Neuroscience 62, 655-666.

Avoli, M., Perreault, P., Olivier, A., Villemure, J., 1988. 4-Aminopyridine induces a long-lasting depolarizing GABA-ergic potential in human neocortical and hippocampal neurons maintained in vitro. Neurosci Lett 94, 327-332.

Ayala, G.F., Dichter, M., Gumnit, R.J., Matsumoto, H., Spencer, W.A., 1973. Genesis of epileptic interictal spikes. New knowledge of cortical feedback systems suggests a neurophysiological explanation of brief paroxysms. Brain Res. 52, 1-17.

Bartos, M., Vida, I., Frotscher, M., Geiger, J., Jonas, P., 2001. Rapid signaling at inhibitory synapses in a dentate gyrus interneuron network. J Neurosci 21, 2687-2698.

Baud, M.O., Kleen, J.K., Mirro, E.A., Andrechak, J.C., King-Stephens, D., Chang, E.F., Rao, V.R., 2018. Multi-day rhythms modulate seizure risk in epilepsy. Nat. Commun. 9, 88.

Beaulieu-Laroche, L., Toloza, E.H.S., van der Goes, M.-S., Lafourcade, M., Barnagian, D., Williams, Z.M., Eskandar, E.N., Frosch, M.P., Cash, S.S., Harnett, M.T., 2018. Enhanced Dendritic Compartmentalization in Human Cortical Neurons. Cell 175, 643-651.e14.

Beenhakker, M.P., Huguenard, J.R., 2009. Neurons that fire together also conspire together: is normal sleep circuitry hijacked to generate epilepsy? Neuron 62, 612-632.

Beltramo, R., D’Urso, G., Dal Maschio, M., Farisello, P., Bovetti, S., Clovis, Y., Lassi, G., Tucci, V., De Pietri Tonelli, D., Fellin, T., 2013. Layer-specific excitatory circuits differentially control recurrent network dynamics in the neocortex. Nat. Neurosci. 16, 227-234.

Bohbot, V.D., Copara, M.S., Gotman, J., Ekstrom, A.D., 2017. Low-frequency theta oscillations in the human hippocampus during real-world and virtual navigation. Nat. Commun. 8, 14415.

Boldog, E., Bakken, T.E., Hodge, R.D., Novotny, M., Aevermann, B.D., Baka, J., Bordé, S., Close, J.L., Diez-Fuertes, F., Ding, S.-L., Faragó, N., Kocsis, Á.K., Kovács, B., Maltzer, Z., McCorrison, J.M., Miller, J.A., Molnár, G., Oláh, G., Ozsvár, A., Rózsa, M., Shehata, S.I., Smith, K.A., Sunkin, S.M., Tran, D.N., Venepally, P., Wall, A., Puskás, L.G., Barzó, P., Steemers, F.J., Schork, N.J., Scheuermann, R.H., Lasken, R.S., Lein, E.S., Tamás, G., 2018. Transcriptomic and morphophysiological evidence for a specialized human cortical GABAergic cell type. Nat. Neurosci. 21, 1185-1195.

Bragin, A., Azizyan, A., Almajano, J., Engel, J., 2009. The cause of the imbalance in the neuronal network leading to seizure activity can be predicted by the electrographic pattern of the seizure onset. J Neurosci 29, 3660-3671.

Bragin, A., Wilson, C.L., Fields, T., Fried, I., Engel, J., 2005. Analysis of seizure onset on the basis of wideband EEG recordings. Epilepsia 46 Suppl 5, 59-63. 
Buschman, T.J., Miller, E.K., 2007. Top-down versus bottom-up control of attention in the prefrontal and posterior parietal cortices. Science 315, 1860-1862.

Buzsáki, G., 2015. Hippocampal sharp wave-ripple: A cognitive biomarker for episodic memory and planning. Hippocampus 25, 1073-1188.

Buzsáki, G., Anastassiou, C.A., Koch, C., 2012. The origin of extracellular fields and currents EEG, ECoG, LFP and spikes 1-14.

Buzsáki, G., Wang, X.-J., 2012. Mechanisms of gamma oscillations. Annu. Rev. Neurosci. 35, 203225.

Canolty, R.T., Edwards, E., Dalal, S.S., Soltani, M., Nagarajan, S.S., Kirsch, H.E., Berger, M.S., Barbaro, N.M., Knight, R.T., 2006. High gamma power is phase-locked to theta oscillations in human neocortex. Science 313, 1626-1628.

Cash, S.S., Halgren, E., Dehghani, N., Rossetti, A.O., Thesen, T., Wang, C., Devinsky, O., Kuzniecky, R., Doyle, W., Madsen, J.R., Bromfield, E., Eross, L., Halász, P., Karmos, G., Csercsa, R., Wittner, L., Ulbert, I., 2009. The human K-complex represents an isolated cortical down-state. Science 324, 1084-1087.

Chauvette, S., Volgushev, M., Timofeev, I., 2010. Origin of active states in local neocortical networks during slow sleep oscillation. Cereb. Cortex N. Y. N 1991 20, 2660-2674.

Clemens, Z., Mölle, M., Eross, L., Barsi, P., Halász, P., Born, J., 2007. Temporal coupling of parahippocampal ripples, sleep spindles and slow oscillations in humans. Brain J. Neurol. 130, 2868-2878.

Cohen, I., Huberfeld, G., Miles, R., 2006. Emergence of disinhibition-induced synchrony in the CA3 region of the guinea pig hippocampus in vitro. J. Physiol. 570, 583-594.

Cohen, I., Navarro, V., Clemenceau, S., Baulac, M., Miles, R., 2002. On the origin of interictal activity in human temporal lobe epilepsy in vitro. Science 298, 1418-1421.

Conti, L., Palma, E., Roseti, C., Lauro, C., Cipriani, R., de Groot, M., Aronica, E., Limatola, C., 2011. Anomalous levels of $\mathrm{Cl}$ - transporters cause a decrease of GABAergic inhibition in human peritumoral epileptic cortex. Epilepsia 52, 1635-1644.

Craig, M.T., McBain, C.J., 2014. The emerging role of GABAB receptors as regulators of network dynamics: fast actions from a "slow" receptor? Curr. Opin. Neurobiol. 26, 15-21.

Crunelli, V., Hughes, S.W., 2010. The slow $(<1 \mathrm{~Hz})$ rhythm of non-REM sleep: a dialogue between three cardinal oscillators. Nat. Neurosci. 13, 9-17.

Csercsa, R., Dombovári, B., Fabó, D., Wittner, L., Eross, L., Entz, L., Sólyom, A., Rásonyi, G., Szucs, A., Kelemen, A., Jakus, R., Juhos, V., Grand, L., Magony, A., Halász, P., Freund, T.F., Maglóczky, Z., Cash, S.S., Papp, L., Karmos, G., Halgren, E., Ulbert, I., 2010. Laminar analysis of slow wave activity in humans. Brain J. Neurol. 133, 2814-2829.

Curtis, M. de, Avoli, M., 2016. GABAergic networks jump-start focal seizures. Epilepsia 57, 679687. 
D'Antuono, M., Louvel, J., Kohling, R., Mattia, D., Bernasconi, A., Olivier, A., Turak, B., Devaux, A., Pumain, R., Avoli, M., 2004. GABAA receptor-dependent synchronization leads to ictogenesis in the human dysplastic cortex. Brain J. Neurol. 127, 1626-1640.

de Curtis, M., Avoli, M., 2015. Initiation, Propagation, and Termination of Partial (Focal) Seizures. Cold Spring Harb. Perspect. Med. 5, a022368.

de la Prida, L.M., 2018. A Lunatic Dance: Circadian and Multidien Structures of Seizure Timing. Epilepsy Curr. 18, 194-196.

de La Prida, L.M., Huberfeld, G., Cohen, I., Miles, R., 2006. Threshold behavior in the initiation of hippocampal population bursts. Neuron 49, 131-142.

DeFelipe, J., Garcia Sola, R., Marco, P., del Río, M.R., Pulido, P., Ramón y Cajal, S., 1993. Selective changes in the microorganization of the human epileptogenic neocortex revealed by parvalbumin immunoreactivity. Cereb. Cortex N. Y. N 1991 3, 39-48.

DeFelipe, J., Huntley, G.W., del Río, M.R., Sola, R.G., Morrison, J.H., 1994. Microzonal decreases in the immunostaining for non-NMDA ionotropic excitatory amino acid receptor subunits GluR 2/3 and GluR 5/6/7 in the human epileptogenic neocortex. Brain Res. 657, 150-158.

del Río, M.R., DeFelipe, J., 1997. Synaptic connections of calretinin-immunoreactive neurons in the human neocortex. J. Neurosci. Off. J. Soc. Neurosci. 17, 5143-5154.

Destexhe, A., 1998. Spike-and-wave oscillations based on the properties of GABAB receptors. J. Neurosci. Off. J. Soc. Neurosci. 18, 9099-9111.

Dossi, E., Blauwblomme, T., Moulard, J., Chever, O., Vasile, F., Guinard, E., Le Bert, M., Couillin, I., Pallud, J., Capelle, L., Huberfeld, G., Rouach, N., 2018. Pannexin-1 channels contribute to seizure generation in human epileptic brain tissue and in a mouse model of epilepsy. Sci. Transl.

Dossi, E., Blauwblomme, T., Nabbout, R., Huberfeld, G., Rouach, N., 2014. Multi-electrode Array Recordings of Human Epileptic Postoperative Cortical Tissue. J. Vis. Exp. e51870-e51870.

Dzhala, V., Talos, D., Sdrulla, D., Brumback, A., Mathews, G., Benke, T., Delpire, E., Jensen, F., Staley, K., 2005. NKCC1 transporter facilitates seizures in the developing brain. Nat Med 11, 12051213.

Dzhala, V., Valeeva, G., Glykys, J., Khazipov, R., Staley, K., 2012. Traumatic Alterations in GABA Signaling Disrupt Hippocampal Network Activity in the Developing Brain. J Neurosci 32, 40174031.

Eissa, T.L., Dijkstra, K., Brune, C., Emerson, R.G., van Putten, M.J.A.M., Goodman, R.R., McKhann, G.M., Schevon, C.A., van Drongelen, W., van Gils, S.A., 2017. Cross-scale effects of neural interactions during human neocortical seizure activity. Proc. Natl. Acad. Sci. U. S. A. 114, 10761-10766.

Elahian, B., Lado, N.E., Mankin, E., Vangala, S., Misra, A., Moxon, K., Fried, I., Sharan, A., Yeasin, M., Staba, R., Bragin, A., Avoli, M., Sperling, M.R., Engel, J., Weiss, S.A., 2018. Low-voltage fast seizures in humans begin with increased interneuron firing. Ann. Neurol. 84, 588-600.

Ellender, T.J., Nissen, W., Colgin, L.L., Mann, E.O., Paulsen, O., 2010. Priming of hippocampal 
population bursts by individual perisomatic-targeting interneurons. J. Neurosci. Off. J. Soc. Neurosci. 30, 5979-5991.

Eugène, E., Cluzeaud, F., Cifuentes-Diaz, C., Fricker, D., Le Duigou, C., Clemenceau, S., Baulac, M., Poncer, J.-C., Miles, R., 2014. An organotypic brain slice preparation from adult patients with temporal lobe epilepsy. J. Neurosci. Methods 235, 234-244.

Eyal, G., Verhoog, M.B., Testa-Silva, G., Deitcher, Y., Lodder, J.C., Benavides-Piccione, R., Morales, J., DeFelipe, J., de Kock, C.P., Mansvelder, H.D., Segev, I., 2016. Unique membrane properties and enhanced signal processing in human neocortical neurons. eLife 5.pii: e16553

Fell, J., Klaver, P., Lehnertz, K., Grunwald, T., Schaller, C., Elger, C.E., Fernández, G., 2001. Human memory formation is accompanied by rhinal-hippocampal coupling and decoupling. Nat. Neurosci. 4, 1259-1264.

Feyissa, A.M., Worrell, G.A., Tatum, W.O., Mahato, D., Brinkmann, B.H., Rosenfeld, S.S., ReFaey, K., Bechtle, P.S., Quinones-Hinojosa, A., 2018. High-frequency oscillations in awake patients undergoing brain tumor-related epilepsy surgery. Neurology. 90, e1119-e1125.

Fisahn, A., Contractor, A., Traub, R.D., Buhl, E.H., Heinemann, S.F., McBain, C.J., 2004. Distinct roles for the kainate receptor subunits GluR5 and GluR6 in kainate-induced hippocampal gamma oscillations. J. Neurosci. Off. J. Soc. Neurosci. 24, 9658-9668.

Florez, C.M., McGinn, R.J., Lukankin, V., Marwa, I., Sugumar, S., Dian, J., Hazrati, L.-N., Carlen, P.L., Zhang, L., Valiante, T.A., 2015. In Vitro Recordings of Human Neocortical Oscillations. Cereb. Cortex 25,578-97.

Foehring, R.C., Lorenzon, N.M., Herron, P., Wilson, C.J., 1991. Correlation of physiologically and morphologically identified neuronal types in human association cortex in vitro. J. Neurophysiol. 66, 1825-1837.

Foffani, G., Uzcategui, Y.G., Gal, B., Menendez de la Prida, L., 2007. Reduced spike-timing reliability correlates with the emergence of fast ripples in the rat epileptic hippocampus. Neuron 55 , 930-941.

Fuchs, E.C., Zivkovic, A.R., Cunningham, M.O., Middleton, S., Lebeau, F.E.N., Bannerman, D.M., Rozov, A., Whittington, M.A., Traub, R.D., Rawlins, J.N.P., Monyer, H., 2007. Recruitment of parvalbumin-positive interneurons determines hippocampal function and associated behavior. Neuron 53, 591-604.

Fujiwara-Tsukamoto, Y., Isomura, Y., Imanishi, M., Fukai, T., Takada, M., 2007. Distinct types of ionic modulation of GABA actions in pyramidal cells and interneurons during electrical induction of hippocampal seizure-like network activity. Eur J Neurosci 25, 2713-2725.

Gabbott, P.L., Jays, P.R., Bacon, S.J., 1997. Calretinin neurons in human medial prefrontal cortex (areas 24a,b,c, 32', and 25). J. Comp. Neurol. 381, 389-410.

Gabriel, S., Njunting, M., Pomper, J., Merschhemke, M., Sanabria, E., Eilers, A., Kivi, A., Zeller, M., Meencke, H., Cavalheiro, E., Heinemann, U., Lehmann, T., 2004. Stimulus and potassiuminduced epileptiform activity in the human dentate gyrus from patients with and without hippocampal sclerosis. J Neurosci 24, 10416-10430. 
Gelinas, J.N., Khodagholy, D., Thesen, T., Devinsky, O., Buzsáki, G., 2016. Interictal epileptiform discharges induce hippocampal-cortical coupling in temporal lobe epilepsy. Nat. Med. 22, 641648.

Gigout, S., Louvel, J., Kawasaki, H., D’Antuono, M., Armand, V., Kurcewicz, I., Olivier, A., Laschet, J., Turak, B., Devaux, B., Pumain, R., Avoli, M., 2006. Effects of gap junction blockers on human neocortical synchronization. Neurobiol Dis 22, 496-508.

Gnatkovsky, V., Librizzi, L., Trombin, F., de Curtis, M., 2008. Fast activity at seizure onset is mediated by inhibitory circuits in the entorhinal cortex in vitro. Ann. Neurol. 64, 674-686.

Gotman, J., Levtova, V., Olivier, A., 1995. Frequency of the electroencephalographic discharge in seizures of focal and widespread onset in intracerebral recordings. Epilepsia 36, 697-703.

Graebenitz, S., Kedo, O., Speckmann, E.-J., Gorji, A., Panneck, H., Hans, V., Palomero-Gallagher, N., Schleicher, A., Zilles, K., Pape, H.-C., 2011. Interictal-like network activity and receptor expression in the epileptic human lateral amygdala. Brain 134, 2929-2947.

Haegens, S., Händel, B.F., Jensen, O., 2011. Top-down controlled alpha band activity in somatosensory areas determines behavioral performance in a discrimination task. J. Neurosci. Off. J. Soc. Neurosci. 31, 5197-5204.

Hájos, N., Mody, I., 2009. Establishing a physiological environment for visualized in vitro brain slice recordings by increasing oxygen supply and modifying aCSF content. J. Neurosci. Methods. 183, 107-13.

Halgren, M., Fabó, D., Ulbert, I., Madsen, J.R., Erőss, L., Doyle, W.K., Devinsky, O., Schomer, D., Cash, S.S., Halgren, E., 2018. Superficial Slow Rhythms Integrate Cortical Processing in Humans. Sci. Rep. 8, 2055.

Hangya, B., Tihanyi, B.T., Entz, L., Fabó, D., Erőss, L., Wittner, L., Jakus, R., Varga, V., Freund, T.F., Ulbert, I., 2011. Complex propagation patterns characterize human cortical activity during slow-wave sleep. J. Neurosci. Off. J. Soc. Neurosci. 31, 8770-8779.

Heinemann, U., Albrecht, D., Köhr, G., Rausche, G., Stabel, J., Wisskirchen, T., 1992. Low-Ca(2+)induced epileptiform activity in rat hippocampal slices. Epilepsy Res. Suppl. 8, 147-155.

Huberfeld, G., de la Prida, L.M., Pallud, J., Cohen, I., Le Van Quyen, M., Adam, C., Clemenceau, S., Baulac, M., Miles, R., 2011. Glutamatergic pre-ictal discharges emerge at the transition to seizure in human epilepsy. Nat. Neurosci 14, 627-634.

Huberfeld, G., Le Duigou, Caroline, Le Van Quyen, M., Navarro, V., Baulac, M., Miles, R., 2013. The Paradox of the Paroxysm: Can Seizure Precipitants Help Explain Human Ictogenesis? Neuroscientist 19, 523-40.

Huberfeld, G., Wittner, L., Clemenceau, S., Baulac, M., Kaila, K., Miles, R., Rivera, C., 2007. Perturbed chloride homeostasis and GABAergic signaling in human temporal lobe epilepsy. J. Neurosci. Off. J. Soc. Neurosci. 27, 9866-9873.

Huchzermeyer, C., Albus, K., Gabriel, H.-J., Otáhal, J., Taubenberger, N., Heinemann, U., Kovács, R., Kann, O., 2008. Gamma oscillations and spontaneous network activity in the hippocampus are highly sensitive to decreases in $\mathrm{pO} 2$ and concomitant changes in mitochondrial redox state. J. 
Neurosci. Off. J. Soc. Neurosci. 28, 1153-1162.

Hwa, G.G., Avoli, M., 1992. Excitatory synaptic transmission mediated by NMDA and non-NMDA receptors in the superficial/middle layers of the epileptogenic human neocortex maintained in vitro. Neurosci. Lett. 143, 83-86.

Isokawa, M., Fried, I., 1996. Extracellular slow negative transient in the dentate gyrus of human epileptic hippocampus in vitro. NSC 72, 31-37.

Jacobs, J., Kahana, M.J., Ekstrom, A.D., Fried, I., 2007. Brain oscillations control timing of singleneuron activity in humans. J. Neurosci. Off. J. Soc. Neurosci. 27, 3839-3844.

Jandova, K., Pasler, D., Antonio, L., Raue, C., Ji, S., Njunting, M., Kann, O., Kovacs, R., Meencke, H., Cavalheiro, E., Heinemann, U., Gabriel, S., Lehmann, T., 2006. Carbamazepine-resistance in the epileptic dentate gyrus of human hippocampal slices. Brain J. Neurol. 129, 3290-3306.

Jansen, L.A., Peugh, L.D., Roden, W.H., Ojemann, J.G., 2010. Impaired maturation of cortical $\mathrm{GABA}(\mathrm{A})$ receptor expression in pediatric epilepsy. Epilepsia 51, 1456-1467.

Jefferys, J.G.R., Menendez de la Prida, L., Wendling, F., Bragin, A., Avoli, M., Timofeev, I., Lopes da Silva, F.H., 2012. Mechanisms of physiological and epileptic HFO generation. Prog. Neurobiol. 98, 250-264.

Jensen, O., Colgin, L.L., 2007. Cross-frequency coupling between neuronal oscillations. Trends Cogn. Sci. 11, 267-269.

Jirsa, V.K., Stacey, W.C., Quilichini, P.P., Ivanov, A.I., Bernard, C., 2014. On the nature of seizure dynamics. Brain J. Neurol. 137, 2210-2230.

Jiruska, P., Finnerty, G.T., Powell, A.D., Lofti, N., Cmejla, R., Jefferys, J.G.R., 2010. Epileptic highfrequency network activity in a model of non-lesional temporal lobe epilepsy. Brain J. Neurol. 133, 1380-1390.

Jobst, B.C., Engel, J., 2015. Is it time to replace epileptic spikes with fast ripples? Neurology 85, 114-115.

Johnston, D., Brown, T.H., 1981. Giant synaptic potential hypothesis for epileptiform activity. Science 211, 294-297.

Jones, R.S.G., da Silva, A.B., Whittaker, R.G., Woodhall, G.L., Cunningham, M.O., 2016. Human brain slices for epilepsy research: Pitfalls, solutions and future challenges. J. Neurosci. Methods 260, 221-232.

Jutras, M.J., Fries, P., Buffalo, E.A., 2013. Oscillatory activity in the monkey hippocampus during visual exploration and memory formation. Proc. Natl. Acad. Sci. U. S. A. 110, 13144-13149.

Karlócai, M.R., Wittner, L., Tóth, K., Maglóczky, Z., Katarova, Z., Rásonyi, G., Erőss, L., Czirják, S., Halász, P., Szabó, G., Payne, J.A., Kaila, K., Freund, T.F., 2016. Enhanced expression of potassium-chloride cotransporter KCC2 in human temporal lobe epilepsy. Brain Struct. Funct. 221, 3601-3615.

Keller, C.J., Truccolo, W., Gale, J.T., Eskandar, E., Thesen, T., Carlson, C., Devinsky, O., 
Kuzniecky, R., Doyle, W.K., Madsen, J.R., Schomer, D.L., Mehta, A.D., Brown, E.N., Hochberg, L.R., Ulbert, I., Halgren, E., Cash, S.S., 2010. Heterogeneous neuronal firing patterns during interictal epileptiform discharges in the human cortex. Brain J. Neurol. 133, 1668-1681.

Kim, E.J., Juavinett, A.L., Kyubwa, E.M., Jacobs, M.W., Callaway, E.M., 2015. Three Types of Cortical Layer 5 Neurons That Differ in Brain-wide Connectivity and Function. Neuron 88, 12531267.

Kivi, A., Lehmann, T.N., Kovacs, R., Eilers, A., Jauch, R., Meencke, H.J., von Deimling, A., Heinemann, U., Gabriel, S., 2000. Effects of barium on stimulus-induced rises of $[\mathrm{K}+] \mathrm{o}$ in human epileptic non-sclerotic and sclerotic hippocampal area CA1. Eur. J. Neurosci. 12, 2039-2048.

Klaft, Z.-J., Hollnagel, J.-O., Salar, S., Calişkan, G., Schulz, S.B., Schneider, U.C., Horn, P., Koch, A., Holtkamp, M., Gabriel, S., Gerevich, Z., Heinemann, U., 2016. Adenosine A1 receptor-mediated suppression of carbamazepine-resistant seizure-like events in human neocortical slices. Epilepsia 57, 746-756.

Kohling, R., Avoli, M., 2006. Methodological approaches to exploring epileptic disorders in the human brain in vitro. J Neurosci Methods 155, 1-19.

Kohling, R., Lucke, A., Straub, H., Speckmann, E.J., Tuxhorn, I., Wolf, P., Pannek, H., Oppel, F., 1998. Spontaneous sharp waves in human neocortical slices excised from epileptic patients. Brain J. Neurol. 121 ( Pt 6), 1073-1087.

Kohling, R., Qu, M., Zilles, K., Speckmann, E., 1999. Current-source-density profiles associated with sharp waves in human epileptic neocortical tissue. Neuroscience 94, 1039-1050.

Kramer, M.A., Roopun, A.K., Carracedo, L.M., Traub, R.D., Whittington, M.A., Kopell, N.J., 2008. Rhythm generation through period concatenation in rat somatosensory cortex. PLoS Comput. Biol. 4, e1000169.

Kucewicz, M.T., Cimbalnik, J., Matsumoto, J.Y., Brinkmann, B.H., Bower, M.R., Vasoli, V., Sulc, V., Meyer, F., Marsh, W.R., Stead, S.M., Worrell, G.A., 2014. High frequency oscillations are associated with cognitive processing in human recognition memory. Brain J. Neurol. 137, $2231-$ 2244.

Kuhlmann, L., Lehnertz, K., Richardson, M.P., Schelter, B., Zaveri, H.P., 2018. Seizure prediction - ready for a new era. Nat. Rev. Neurol. 14, 618-630.

Lakatos, P., Shah, A.S., Knuth, K.H., Ulbert, I., Karmos, G., Schroeder, C.E., 2005. An oscillatory hierarchy controlling neuronal excitability and stimulus processing in the auditory cortex. J. Neurophysiol. 94, 1904-1911.

Lamberink, H.J., Otte, W.M., Geerts, A.T., Pavlovic, M., Ramos-Lizana, J., Marson, A.G., Overweg, J., Sauma, L., Specchio, L.M., Tennison, M., Cardoso, T.M.O., Shinnar, S., Schmidt, D., Geleijns, K., Braun, K.P.J., 2017. Individualised prediction model of seizure recurrence and long-term outcomes after withdrawal of antiepileptic drugs in seizure-free patients: a systematic review and individual participant data meta-analysis. Lancet Neurol. 16, 523-531.

Lambrecq, V., Lehongre, K., Adam, C., Frazzini, V., Mathon, B., Clemenceau, S., Hasboun, D., Charpier, S., Baulac, M., Navarro, V., Le Van Quyen, M., 2017. Single-unit activities during the transition to seizures in deep mesial structures. Ann. Neurol. 82, 1022-1028. 
Lancaster, M.A., Knoblich, J.A., 2014. Generation of cerebral organoids from human pluripotent stem cells. Nat. Protoc. 9, 2329-2340.

Le Duigou, C., Bouilleret, V., Miles, R., 2008. Epileptiform activities in slices of hippocampus from mice after intra-hippocampal injection of kainic acid. J. Physiol. 586, 4891-904.

Le Duigou, C., Savary, E., Morin-Brureau, M., Gomez-Dominguez, D., Sobczyk, A., Chali, F., Milior, G., Kraus, L., Meier, J.C., Kullmann, D.M., Mathon, B., de la Prida, L.M., Dorfmuller, G., Pallud, J., Eugène, E., Clemenceau, S., Miles, R., 2018. Imaging pathological activities of human brain tissue in organotypic culture. J. Neurosci. Methods 298, 33-44.

Le Van Quyen, M., Staba, R., Bragin, A., Dickson, C., Valderrama, M., Fried, I., Engel, J., 2010. Large-scale microelectrode recordings of high-frequency gamma oscillations in human cortex during sleep. J. Neurosci. 30, 7770-7782.

Lega, B., Dionisio, S., Bingaman, W., Najm, I., Gonzalez-Martinez, J., 2015. The gamma band effect for episodic memory encoding is absent in epileptogenic hippocampi. Clin. Neurophysiol. Off. J. Int. Fed. Clin. Neurophysiol. 126, 866-872.

Li, C.L., 1959. Cortical intracellular potentials and their responses to strychnine. J. Neurophysiol. 22, 436-450.

Lopez-Pigozzi, D., Laurent, F., Brotons-Mas, J.R., Valderrama, M., Valero, M., Fernandez-Lamo, I., Cid, E., Gomez-Dominguez, D., Gal, B., Menendez de la Prida, L., 2016. Altered Oscillatory Dynamics of CA1 Parvalbumin Basket Cells during Theta-Gamma Rhythmopathies of Temporal Lobe Epilepsy. eNeuro 3. pii: ENEURO.0284-16

Lux, H.D., Heinemann, U., Dietzel, I., 1986. Ionic changes and alterations in the size of the extracellular space during epileptic activity. Adv. Neurol. 44, 619-639.

Mann, E.O., Kohl, M.M., Paulsen, O., 2009. Distinct roles of GABA(A) and GABA(B) receptors in balancing and terminating persistent cortical activity. J. Neurosci. Off. J. Soc. Neurosci. 29, $7513-$ 7518.

Massimini, M., Huber, R., Ferrarelli, F., Hill, S., Tononi, G., 2004. The sleep slow oscillation as a traveling wave. J. Neurosci. Off. J. Soc. Neurosci. 24, 6862-6870.

Mattia, D., Olivier, A., Avoli, M., 1995. Seizure-like discharges recorded in human dysplastic neocortex maintained in vitro. Neurology 45, 1391-1395.

McGinn, R.J., Valiante, T.A., 2014. Phase-amplitude coupling and interlaminar synchrony are correlated in human neocortex. J. Neurosci. Off. J. Soc. Neurosci. 34, 15923-15930.

Menendez de la Prida, L., Benavides-Piccione, R., Sola, R., Pozo, M.A., 2002. Electrophysiological properties of interneurons from intraoperative spiking areas of epileptic human temporal neocortex. Neuroreport 13, 1421-1425.

Menendez de la Prida, L., Bolea, S., Sanchez-Andres, J.V., 1998. Origin of the synchronized network activity in the rabbit developing hippocampus. Eur. J. Neurosci. 10, 899-906.

Menendez de la Prida, L., Staba, R.J., Dian, J.A., 2015. Conundrums of high-frequency oscillations $(80-800 \mathrm{~Hz})$ in the epileptic brain. J. Clin. Neurophysiol. Off. Publ. Am. Electroencephalogr. Soc. 
32, 207-219.

Merricks, E.M., Smith, E.H., McKhann, G.M., Goodman, R.R., Bateman, L.M., Emerson, R.G., Schevon, C.A., Trevelyan, A.J., 2015. Single unit action potentials in humans and the effect of seizure activity. Brain J. Neurol. 138, 2891-2906.

Michalareas, G., Vezoli, J., van Pelt, S., Schoffelen, J.-M., Kennedy, H., Fries, P., 2016. AlphaBeta and Gamma Rhythms Subserve Feedback and Feedforward Influences among Human Visual Cortical Areas. Neuron 89, 384-397.

Mittal, S., Barkmeier, D., Hua, J., Pai, D.S., Fuerst, D., Basha, M., Loeb, J.A., Shah, A.K., 2016. Intracranial EEG analysis in tumor-related epilepsy: Evidence of distant epileptic abnormalities. Clin. Neurophysiol. Off. J. Int. Fed. Clin. Neurophysiol. 127, 238-244.

Mody, I., Lambert, J.D., Heinemann, U., 1987. Low extracellular magnesium induces epileptiform activity and spreading depression in rat hippocampal slices. J Neurophysiol 57, 869-888.

Molnár, G., Oláh, S., Komlósi, G., Füle, M., Szabadics, J., Varga, C., Barzó, P., Tamás, G., 2008. Complex Events Initiated by Individual Spikes in the Human Cerebral Cortex. PLoS Biol. 6, e222.

Muldoon, S.F., Villette, V., Tressard, T., Malvache, A., Reichinnek, S., Bartolomei, F., Cossart, R., 2015. GABAergic inhibition shapes interictal dynamics in awake epileptic mice. Brain J. Neurol. 138, 2875-2890.

Munakata, M., Watanabe, M., Otsuki, T., Nakama, H., Arima, K., Itoh, M., Nabekura, J., linuma, K., Tsuchiya, S., 2007. Altered distribution of KCC2 in cortical dysplasia in patients with intractable epilepsy. Epilepsia 48, 837-844.

Muñoz, A., Méndez, P., DeFelipe, J., Alvarez-Leefmans, F.J., 2007. Cation-Chloride Cotransporters and GABA-ergic Innervation in the Human Epileptic Hippocampus. Epilepsia 48, 663-673.

Niediek, J., Boström, J., Elger, C.E., Mormann, F., 2016. Reliable Analysis of Single-Unit Recordings from the Human Brain under Noisy Conditions: Tracking Neurons over Hours. PloS One 11, e0166598.

Obermayer, J., Heistek, T.S., Kerkhofs, A., Goriounova, N.A., Kroon, T., Baayen, J.C., Idema, S., Testa-Silva, G., Couey, J.J., Mansvelder, H.D., 2018. Lateral inhibition by Martinotti interneurons is facilitated by cholinergic inputs in human and mouse neocortex. Nat. Commun. 9, 4101.

Pallud, J., Audureau, E., Blonski, M., Sanai, N., Bauchet, L., Fontaine, D., Mandonnet, E., Dezamis, E., Psimaras, D., Guyotat, J., Peruzzi, P., Page, P., Gal, B., Parraga, E., Baron, M.H., Vlaicu, M., Guillevin, R., Devaux, B., Duffau, H., Taillandier, L., Capelle, L., Huberfeld, G., 2014a. Epileptic seizures in diffuse low-grade gliomas in adults. Brain 137, 449-462.

Pallud, J., Le Van Quyen, M., Bielle, F., Pellegrino, C., Varlet, P., Labussiere, M., Cresto, N., Dieme, M., Baulac, M., Duyckaerts, C., Kourdougli, N., Chazal, G., Devaux, B., Rivera, C., Miles, R., Capelle, L., Huberfeld, G., 2014b. Cortical GABAergic excitation contributes to epileptic activities around human glioma. Sci. Transl. Med. 6, 244ra89-244ra89.

Pallud, J., Varlet, P., Devaux, B., Geha, S., Badoual, M., Deroulers, C., Page, P., Dezamis, E., Daumas-Duport, C., Roux, F.-X., 2010. Diffuse low-grade oligodendrogliomas extend beyond MRI- 
defined abnormalities. Neurology 74, 1724-1731.

Palma, E., Amici, M., Sobrero, F., Spinelli, G., Di Angelantonio, S., Ragozzino, D., Mascia, A., Scoppetta, C., Esposito, V., Miledi, R., Eusebi, F., 2006. Anomalous levels of Cl- transporters in the hippocampal subiculum from temporal lobe epilepsy patients make GABA excitatory. Proc. Natl. Acad. Sci. 103, 8465-8468.

Palop, J.J., Mucke, L., 2016. Network abnormalities and interneuron dysfunction in Alzheimer disease. Nat. Rev. Neurosci. 17, 777-792.

Palva, J.M., Palva, S., Kaila, K., 2005. Phase synchrony among neuronal oscillations in the human cortex. J. Neurosci. Off. J. Soc. Neurosci. 25, 3962-3972.

Parker, J.J., Lizarraga, M., Waziri, A., Foshay, K.M., 2017. A Human Glioblastoma Organotypic Slice Culture Model for Study of Tumor Cell Migration and Patient-specific Effects of Anti-Invasive Drugs. J. Vis. Exp. JoVE.

Paz, J.T., Huguenard, J.R., 2015. Microcircuits and their interactions in epilepsy: is the focus out of focus? Nat. Neurosci. 18, 351-359.

Pérez-Garci, E., Gassmann, M., Bettler, B., Larkum, M.E., 2006. The GABAB1b isoform mediates long-lasting inhibition of dendritic $\mathrm{Ca} 2+$ spikes in layer 5 somatosensory pyramidal neurons. Neuron 50, 603-616.

Poorthuis, R.B., Muhammad, K., Wang, M., Verhoog, M.B., Junek, S., Wrana, A., Mansvelder, H.D., Letzkus, J.J., 2018. Rapid Neuromodulation of Layer 1 Interneurons in Human Neocortex. Cell Rep. 23, 951-958.

Prince, D., Wong, R., 1981. Human epileptic neurons studied in vitro. Brain Res. 210, 323-333.

Prince, D.A., Connors, B.W., 1986. Mechanisms of interictal epileptogenesis. Adv. Neurol. 44, 275299.

Raghavachari, S., Kahana, M.J., Rizzuto, D.S., Caplan, J.B., Kirschen, M.P., Bourgeois, B., Madsen, J.R., Lisman, J.E., 2001. Gating of human theta oscillations by a working memory task. J. Neurosci. 21, 3175-3183.

Ray, S., Crone, N.E., Niebur, E., Franaszczuk, P.J., Hsiao, S.S., 2008. Neural correlates of highgamma oscillations $(60-200 \mathrm{~Hz})$ in macaque local field potentials and their potential implications in electrocorticography. J. Neurosci. 28, 11526-11536.

Roopun, A.K., Simonotto, J.D., Pierce, M.L., Jenkins, A., Nicholson, C., Schofield, I.S., Whittaker, R.G., Kaiser, M., Whittington, M.A., Traub, R.D., Cunningham, M.O., 2010. A nonsynaptic mechanism underlying interictal discharges in human epileptic neocortex. Proc. Natl. Acad. Sci. U. S. A. $107,338-343$.

Rosenow, F., Luders, H., 2001. Presurgical evaluation of epilepsy. Brain J. Neurol. 124, 16831700 .

Rutecki, P.A., Lebeda, F.J., Johnston, D., 1990. Epileptiform activity in the hippocampus produced by tetraethylammonium. J. Neurophysiol. 64, 1077-1088. 
Rutecki, P.A., Lebeda, F.J., Johnston, D., 1987. 4-Aminopyridine produces epileptiform activity in hippocampus and enhances synaptic excitation and inhibition. J. Neurophysiol. 57, 1911-1924.

Rutecki, P.A., Lebeda, F.J., Johnston, D., 1985. Epileptiform activity induced by changes in extracellular potassium in hippocampus. J. Neurophysiol. 54, 1363-1374.

Rutishauser, U., Ross, I.B., Mamelak, A.N., Schuman, E.M., 2010. Human memory strength is predicted by theta-frequency phase-locking of single neurons. Nature 464, 903-907.

Sakata, S., Harris, K.D., 2009. Laminar structure of spontaneous and sensory-evoked population activity in auditory cortex. Neuron 64, 404-418.

Sanchez-Vives, M.V., McCormick, D.A., 2000. Cellular and network mechanisms of rhythmic recurrent activity in neocortex. Nat. Neurosci. 3, 1027-34.

Schevon, C.A., Weiss, S.A., McKhann, G., Goodman, R.R., Yuste, R., Emerson, R.G., Trevelyan, A.J., 2012. Evidence of an inhibitory restraint of seizure activity in humans. Nat. Commun. 3, 1060.

Schlingloff, D., Káli, S., Freund, T.F., Hájos, N., Gulyás, A.I., 2014. Mechanisms of sharp wave initiation and ripple generation. J. Neurosci. Off. J. Soc. Neurosci. 34, 11385-11398.

Schwartzkroin, P., Haglund, M., 1986. Spontaneous rhythmic synchronous activity in epileptic human and normal monkey temporal lobe. Epilepsia 27, 523-533.

Schwartzkroin, P., Knowles, W., 1984. Intracellular study of human epileptic cortex: in vitro maintenance of epileptiform activity? Science 223, 709-712.

Schwartzkroin, P., Prince, D., 1976. Epileptogenesis in mammalian cortex studied in vitro. Trans Am Neurol Assoc 101, 288-291.

Schwartzkroin, P.A., Turner, D.A., Knowles, W.D., Wyler, A.R., 1983. Studies of human and monkey "epileptic" neocortex in the in vitro slice preparation. Ann. Neurol. 13, 249-257.

Schwarz, N., Hedrich, U.B.S., Schwarz, H., P A, H., Dammeier, N., Auffenberg, E., Bedogni, F., Honegger, J.B., Lerche, H., Wuttke, T.V., Koch, H., 2017. Human Cerebrospinal fluid promotes long-term neuronal viability and network function in human neocortical organotypic brain slice cultures. Sci. Rep. 7, 12249.

Scott, R.C., Menendez de la Prida, L., Mahoney, J.M., Kobow, K., Sankar, R., de Curtis, M., 2018. WONOEP APPRAISAL: The many facets of epilepsy networks. Epilepsia 59, 1475-1483.

Sedigh-Sarvestani, M., Thuku, G.I., Sunderam, S., Parkar, A., Weinstein, S.L., Schiff, S.J., Gluckman, B.J., 2014. Rapid eye movement sleep and hippocampal theta oscillations precede seizure onset in the tetanus toxin model of temporal lobe epilepsy. J. Neurosci. Off. J. Soc. Neurosci. 34, 1105-1114.

Sen, A., Martinian, L., Nikolic, M., Walker, M., Thom, M., Sisodiya, S., 2007. Increased NKCC1 expression in refractory human epilepsy. Epilepsy Res. 74, 220-7.

Shimizu-Okabe, C., Tanaka, M., Matsuda, K., Mihara, T., Okabe, A., Sato, K., Inoue, Y., Fujiwara, T., Yagi, K., Fukuda, A., 2011. KCC2 was downregulated in small neurons localized in epileptogenic human focal cortical dysplasia. Epilepsy Res. 93, 177-184. 
Shuman, T., Amendolara, B., Golshani, P., 2017. Theta Rhythmopathy as a Cause of Cognitive Disability in TLE. Epilepsy Curr. 17, 107-111.

Simeone, T.A., Simeone, K.A., Samson, K.K., Kim, D.Y., Rho, J.M., 2013. Loss of the Kv1.1 potassium channel promotes pathologic sharp waves and high frequency oscillations in in vitro hippocampal slices. Neurobiol. Dis. 54, 68-81.

Simon, A., Traub, R.D., Vladimirov, N., Jenkins, A., Nicholson, C., Whittaker, R.G., Schofield, I., Clowry, G.J., Cunningham, M.O., Whittington, M.A., 2014. Gap junction networks can generate both ripple-like and fast ripple-like oscillations. Eur. J. Neurosci. 39, 46-60.

Spencer, S., Guimaraes, P., Katz, A., Kim, J., Spencer, D., 1992. Morphological patterns of seizures recorded intracranially. Epilepsia 33, 537-545.

Staba, R., Frighetto, L., Behnke, E., Mathern, G., Fields, T., Bragin, A., Ogren, J., Fried, I., Wilson, C., Engel, J., 2007. Increased Fast ripple to ripple Ratios Correlate with Reduced Hippocampal Volumes and Neuron Loss in Temporal Lobe Epilepsy Patients. Epilepsia 48, 2130-8.

Staba, R., Wilson, C., Bragin, A., Fried, I., Engel, J., 2002. Sleep states differentiate single neuron activity recorded from human epileptic hippocampus, entorhinal cortex, and subiculum. J Neurosci 22, 5694-5704.

Staresina, B.P., Bergmann, T.O., Bonnefond, M., van der Meij, R., Jensen, O., Deuker, L., Elger, C.E., Axmacher, N., Fell, J., 2015. Hierarchical nesting of slow oscillations, spindles and ripples in the human hippocampus during sleep. Nat. Neurosci. 18, 1679-1686.

Steriade, M., Timofeev, I., Grenier, F., 2001. Natural waking and sleep states: a view from inside neocortical neurons. J. Neurophysiol. 85, 1969-1985.

Szabadics, J., Tamas, G., Soltesz, I., 2007. Different transmitter transients underlie presynaptic cell type specificity of GABAA,slow and GABAA,fast. Proc Natl Acad Sci U A 104, 14831-14836.

Szabadics, J., Varga, C., Molnar, G., Olah, S., Barzo, P., Tamas, G., 2006. Excitatory effect of GABAergic axo-axonic cells in cortical microcircuits. Science 311, 233-235.

Szegedi, V., Molnár, G., Paizs, M., Csakvari, E., Barzó, P., Tamás, G., Lamsa, K., 2017. HighPrecision Fast-Spiking Basket Cell Discharges during Complex Events in the Human Neocortex. eNeuro 4.

Szegedi, V., Paizs, M., Csakvari, E., Molnar, G., Barzo, P., Tamas, G., Lamsa, K., 2016. Plasticity in Single Axon Glutamatergic Connection to GABAergic Interneurons Regulates Complex Events in the Human Neocortex. PLoS Biol. 14, e2000237.

Talos, D.M., Sun, H., Kosaras, B., Joseph, A., Folkerth, R.D., Poduri, A., Madsen, J.R., Black, P.M., Jensen, F.E., 2012. Altered inhibition in tuberous sclerosis and type Ilb cortical dysplasia. Ann. Neurol. 71, 539-551.

Tamás, G., Lorincz, A., Simon, A., Szabadics, J., 2003. Identified sources and targets of slow inhibition in the neocortex. Science 299, 1902-1905.

Teleńczuk, B., Dehghani, N., Le Van Quyen, M., Cash, S.S., Halgren, E., Hatsopoulos, N.G., Destexhe, A., 2017. Local field potentials primarily reflect inhibitory neuron activity in human and 
monkey cortex. Sci. Rep. 7, 40211.

Tort, A.B.L., Scheffer-Teixeira, R., Souza, B.C., Draguhn, A., Brankačk, J., 2013. Theta-associated high-frequency oscillations $(110-160 \mathrm{~Hz})$ in the hippocampus and neocortex. Prog. Neurobiol. 100, $1-14$.

Tóth, K., Hofer, K.T., Kandrács, Á., Entz, L., Bagó, A., Erőss, L., Jordán, Z., Nagy, G., Sólyom, A., Fabó, D., Ulbert, I., Wittner, L., 2018. Hyperexcitability of the network contributes to synchronization processes in the human epileptic neocortex. J. Physiol. 596, 317-342.

Truccolo, W., Ahmed, O.J., Harrison, M.T., Eskandar, E.N., Cosgrove, G.R., Madsen, J.R., Blum, A.S., Potter, N.S., Hochberg, L.R., Cash, S.S., 2014. Neuronal ensemble synchrony during human focal seizures. J. Neurosci. Off. J. Soc. Neurosci. 34, 9927-9944.

Truccolo, W., Donoghue, J.A., Hochberg, L.R., Eskandar, E.N., Madsen, J.R., Anderson, W.S., Brown, E.N., Halgren, E., Cash, S.S., 2011. Single-neuron dynamics in human focal epilepsy. Nat. Neurosci. 14, 635-641.

Ulbert, I., Heit, G., Madsen, J., Karmos, G., Halgren, E., 2004. Laminar analysis of human neocortical interictal spike generation and propagation: current source density and multiunit analysis in vivo. Epilepsia 45 Suppl 4, 48-56.

Valero, M., Averkin, R.G., Fernandez-Lamo, I., Aguilar, J., Lopez-Pigozzi, D., Brotons-Mas, J.R., Cid, E., Tamas, G., Menendez de la Prida, L., 2017. Mechanisms for Selective Single-Cell Reactivation during Offline Sharp-Wave Ripples and Their Distortion by Fast Ripples. Neuron 94, 1234-1247.e7.

Valero, M., Cid, E., Averkin, R.G., Aguilar, J., Sanchez-Aguilera, A., Viney, T.J., GomezDominguez, D., Bellistri, E., de la Prida, L.M., 2015. Determinants of different deep and superficial CA1 pyramidal cell dynamics during sharp-wave ripples. Nat. Neurosci. 18, 1281-1290.

Vanhatalo, S., Holmes, M.D., Tallgren, P., Voipio, J., Kaila, K., Miller, J.W., 2003. Very slow EEG responses lateralize temporal lobe seizures: an evaluation of non-invasive DC-EEG. Neurology 60, 1098-1104.

Varga, C., Tamas, G., Barzo, P., Olah, S., Somogyi, P., 2015. Molecular and Electrophysiological Characterization of GABAergic Interneurons Expressing the Transcription Factor COUP-TFII in the Adult Human Temporal Cortex. Cereb. Cortex N. Y. N 1991 25, 4430-4449.

Vida, I., Bartos, M., Jonas, P., 2006. Shunting inhibition improves robustness of gamma oscillations in hippocampal interneuron networks by homogenizing firing rates. Neuron 49, 107-117.

Viitanen, T., Ruusuvuori, E., Kaila, K., Voipio, J., 2010. The K+-Clltextminus cotransporter KCC2 promotes GABAergic excitation in the mature rat hippocampus. J. Physiol. 588, 1527-1540.

Voipio, J., Tallgren, P., Heinonen, E., Vanhatalo, S., Kaila, K., 2003. Millivolt-scale DC shifts in the human scalp EEG: evidence for a nonneuronal generator. J. Neurophysiol. 89, 2208-2214.

Wagner, F.B., Eskandar, E.N., Cosgrove, G.R., Madsen, J.R., Blum, A.S., Potter, N.S., Hochberg, L.R., Cash, S.S., Truccolo, W., 2015. Microscale spatiotemporal dynamics during neocortical propagation of human focal seizures. Neurolmage 122, 114-130. 
Wang, Yi, Xu, C., Xu, Z., Ji, C., Liang, J., Wang, Ying, Chen, B., Wu, X., Gao, F., Wang, S., Guo, Y., Li, X., Luo, J., Duan, S., Chen, Z., 2017. Depolarized GABAergic Signaling in Subicular Microcircuits Mediates Generalized Seizure in Temporal Lobe Epilepsy. Neuron 95, 92-105.e5.

Weiss, S.A., Alvarado-Rojas, C., Bragin, A., Behnke, E., Fields, T., Fried, I., Engel, J., Staba, R., 2016. Ictal onset patterns of local field potentials, high frequency oscillations, and unit activity in human mesial temporal lobe epilepsy. Epilepsia 57, 111-121.

Weiss, S.A., Banks, G.P., McKhann, G.M., Goodman, R.R., Emerson, R.G., Trevelyan, A.J., Schevon, C.A., 2013. Ictal high frequency oscillations distinguish two types of seizure territories in humans. Brain 136, 3796-3808.

Wittner, L., Huberfeld, G., Clemenceau, S., Eross, L., Dezamis, E., Entz, L., Ulbert, I., Baulac, M., Freund, T.F., Maglóczky, Z., Miles, R., 2009. The epileptic human hippocampal cornu ammonis 2 region generates spontaneous interictal-like activity in vitro. Brain 132, 3032-3046.

Worrell, G.A., Gardner, A.B., Stead, S.M., Hu, S., Goerss, S., Cascino, G.J., Meyer, F.B., Marsh, R., Litt, B., 2008. High-frequency oscillations in human temporal lobe: simultaneous microwire and clinical macroelectrode recordings. Brain J. Neurol. 131, 928-937.

Wozny, C., Kivi, A., Lehmann, T.-N., Dehnicke, C., Heinemann, U., Behr, J., 2003. Comment on "On the origin of interictal activity in human temporal lobe epilepsy in vitro." Science 301, 463; author reply 463.

Zhang, H., Fell, J., Axmacher, N., 2018. Electrophysiological mechanisms of human memory consolidation. Nat. Commun. 9, 4103.

Ziburkus, J., 2006. Interneuron and Pyramidal Cell Interplay During In Vitro Seizure-Like Events. J. Neurophysiol. 95, 3948-3954.

Zijlmans, M., Jiruska, P., Zelmann, R., Leijten, F.S.S., Jefferys, J.G.R., Gotman, J., 2012. Highfrequency oscillations as a new biomarker in epilepsy. Ann. Neurol. 71, 169-178. 


\section{Figure caption.}

Figure 1. Various oscillatory patterns are generated by the human cortex both in vivo and in vitro. A, Electrocorticographic (ECOG) recording of frontal cortex surrounding a glioma using a combined macro (3 mm - peripheral contacts) and micro (1 mm central contacts) electrodes (sampling rate: $20000 \mathrm{~Hz}$ ) in awake non-anesthetized condition to perform functional mapping. Filtering the raw signal unravels fast oscillations $(100-200 \mathrm{~Hz})$ coupled to slow recurring waves $(1-2 \mathrm{~Hz})$ and interacting with intermediate rhythms $(7-15 \mathrm{~Hz})$. The time frequency map for frequencies $>50 \mathrm{~Hz}$ is shown at bottom. B, In vitro multielectrode array (MEA) recordings of a temporal lobe cortical slice from an epileptic patient (sampling rate: $10000 \mathrm{~Hz}$ ) showing recurring slow waves $(1-2 \mathrm{~Hz})$ of interictal-like discharges associated to fast oscillations $(100-150 \mathrm{~Hz})$.

Figure 2. Physiological-like oscillations and associated pathological mechanisms. A, Local microcircuits support generation of gamma rhythms $(40-80 \mathrm{~Hz})$ by pyramidal-interneurons (PING) and interneuron-interneuron (ING) interactions. Ripples $(>150 \mathrm{~Hz})$ involve similar interactions brought about by recurrent pyramidal connections. B, Inter-laminar and inter-regional connections in interaction with subcortical structures facilitate modulation of fast local oscillations by slower $(<1$ $\mathrm{Hz}$ ) and intermediate rhythms, such as theta $(4-12 \mathrm{~Hz})$. C, Physiological- and pathological forms of oscillations can be interpreted as extremes of a continuum that characterize different activity features.

Table. Electrophysiological oscillations in human brain slices recorded in physiological-like conditions 


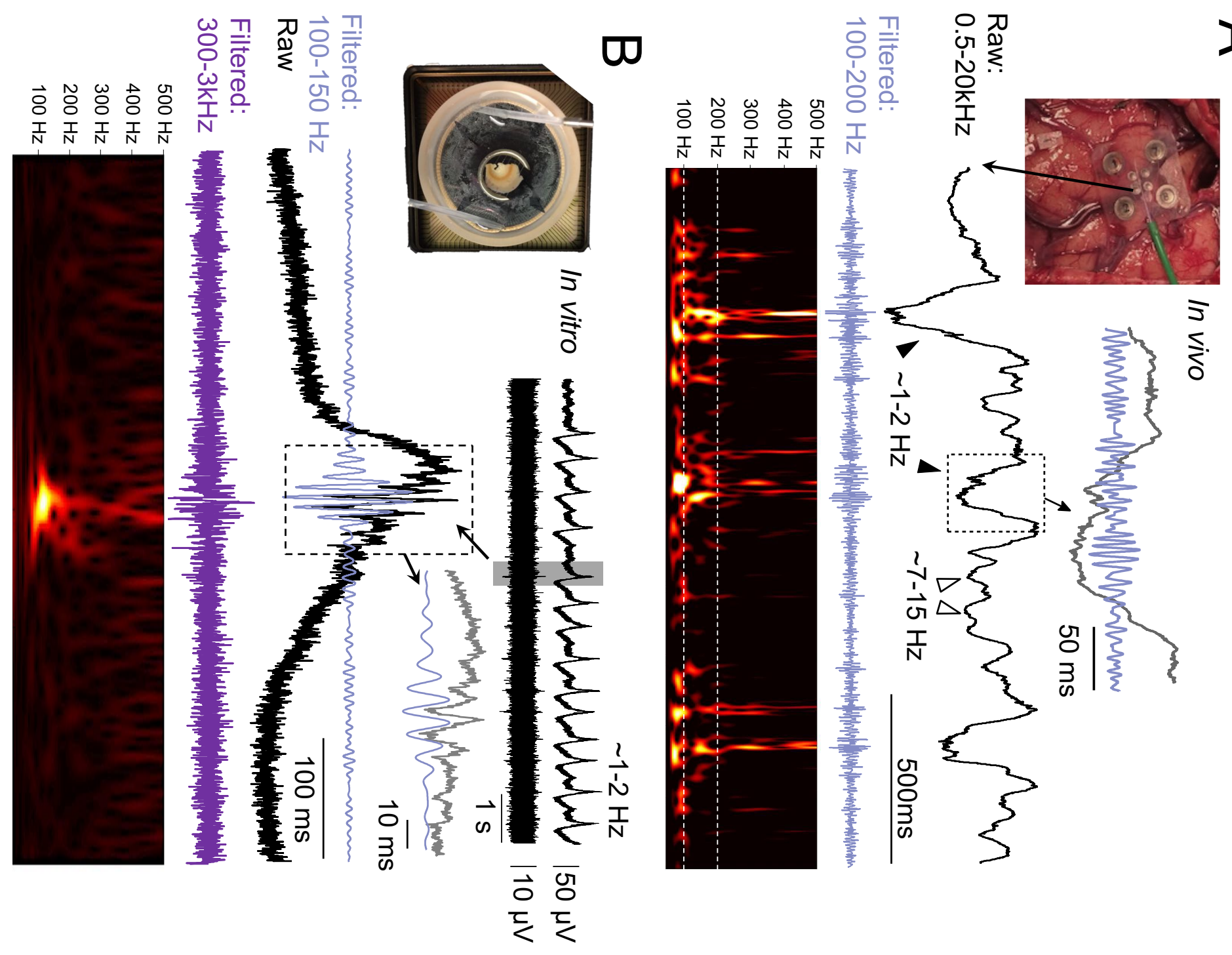




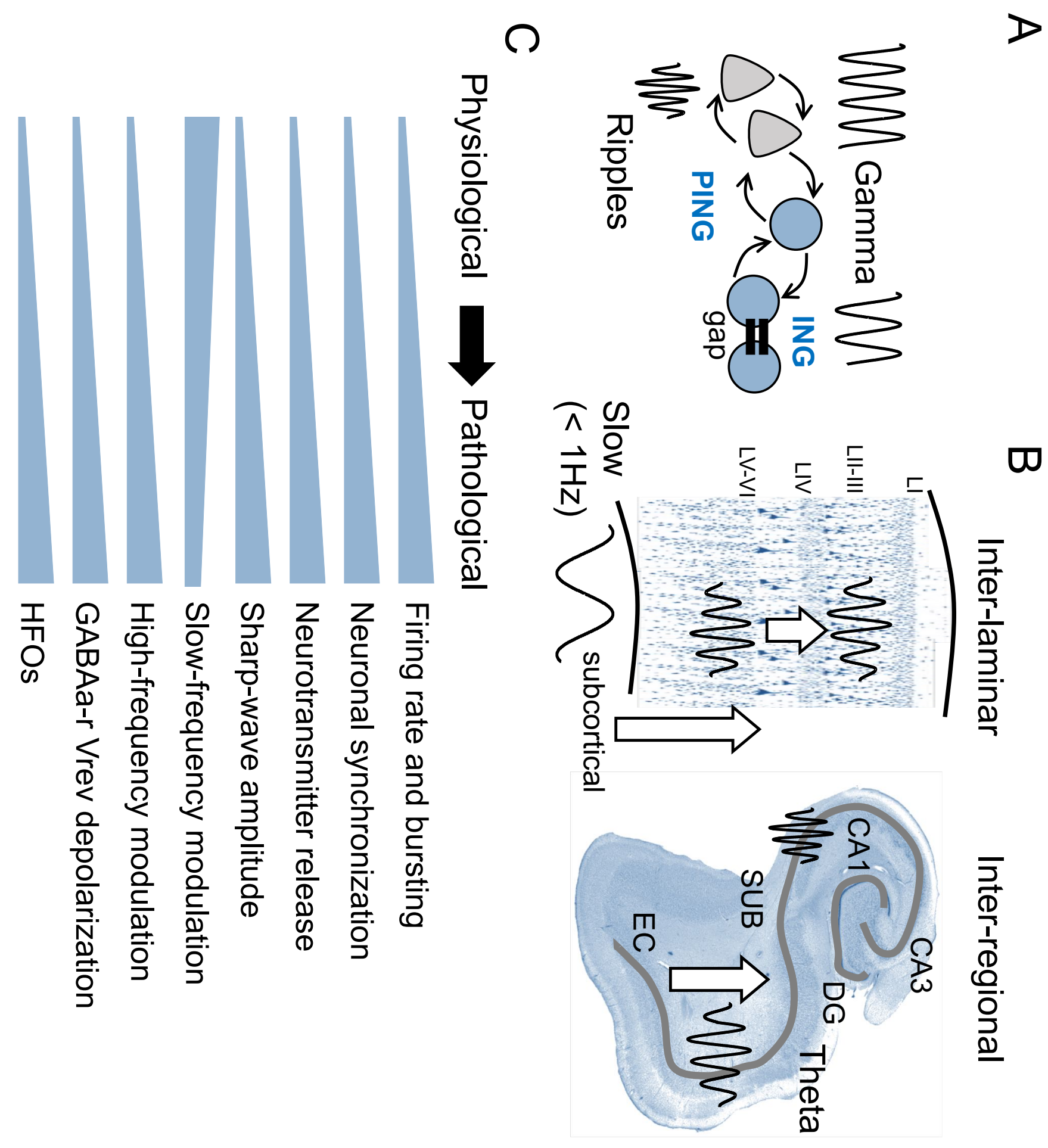




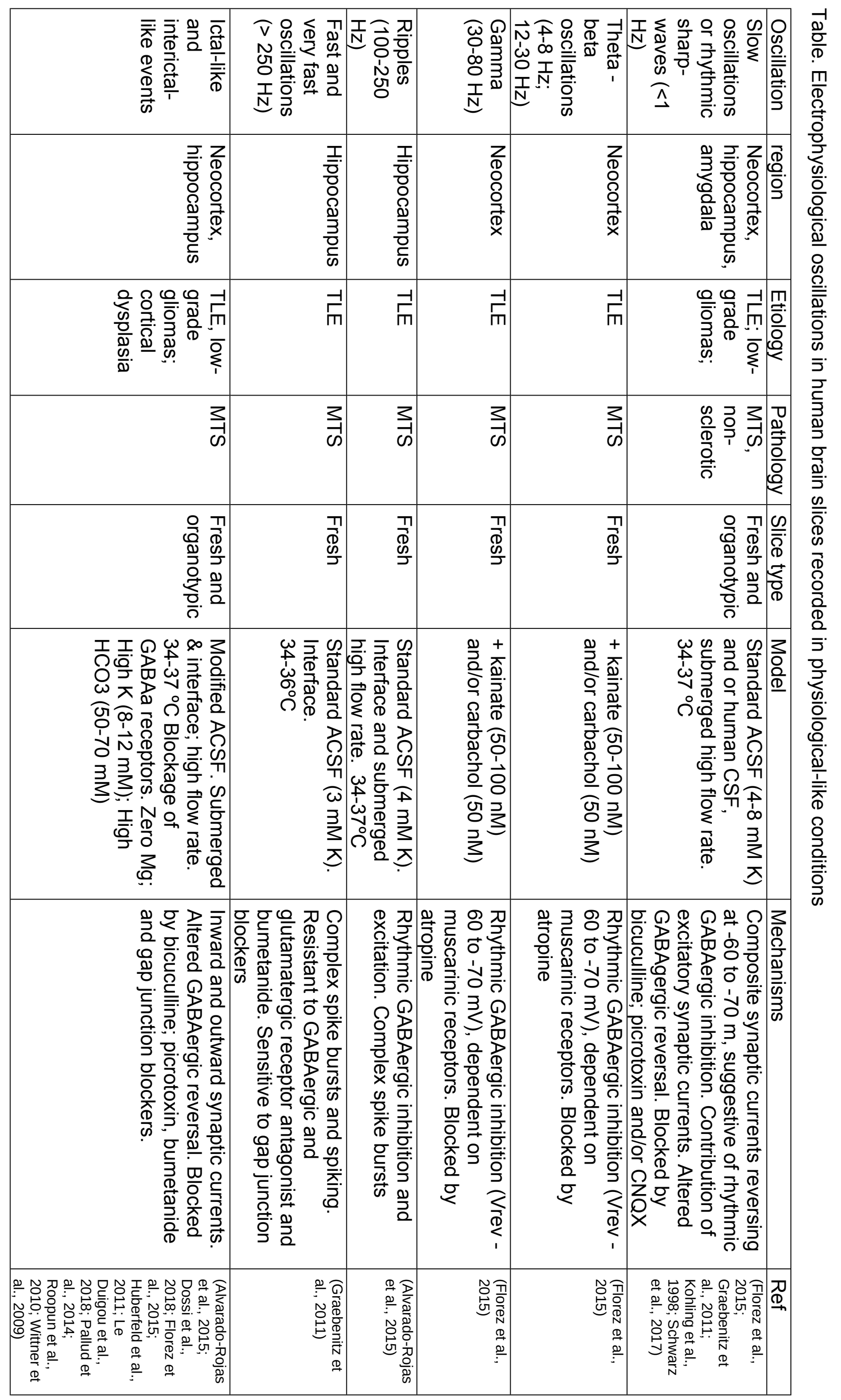

